\title{
Effects of courtyard and opening on a rectangular plan shaped tall building under wind load
}

\author{
Prasenjit Sanyal $^{1}\left[\right.$. Sujit Kumar Dalui ${ }^{1}$
}

Received: 18 April 2017 / Accepted: 23 May 2018 / Published online: 4 June 2018

(c) The Author(s) 2018

\begin{abstract}
The variation in pressure on various faces of a rectangular shaped tall building due to the presence of courtyard and opening is examined for a boundary layer flow condition corresponding to terrain category II of IS:875 (Part 3)-2015. ANSYS CFX is used for the simulation. Two turbulence models, $k-\varepsilon$ and shear stress transport (SST), are used in the validation of ANSYS CFX, and the results are compared with different international standards. In the presence of courtyard and opening, interesting and unusual pressure distributions on certain faces are observed due to a self-interference effect. Flow patterns around the building for different areas of opening are also studied to explain the phenomena occurring around the building. Furthermore, the polynomial expressions for calculating force coefficients and mean pressure coefficients of each face for different angles of attack and areas of opening are proposed using least-squares regression method. Accuracy of the fitted polynomials is measured by $R^{2}$ value.
\end{abstract}

Keywords Computational fluid dynamics · Courtyard · Opening · Mean pressure coefficients · Least-squares regression polynomial

\section{Introduction}

With the continuous improvement of modern analysis and design technology and in the context of huge urban growth, the number of tall buildings and skyscrapers is increasing day by day. Wind engineering is also getting much more attention, as the need for study of the possible inconvenience, damage or benefits from wind on these tall buildings arises. Such tall buildings may be of a conventional or uncommon shape in plan. Building with inner courtyard is not very uncommon as courtyard is an integral component of constructed dwellings from old human civilizations such as Indus Valley, Chinese, Egyptian or Mesopotamian.

Courtyard is an unroofed area which is partially or completely enclosed by walls or buildings in a large house or housing complex. Courtyard is generally used in buildings

Prasenjit Sanyal

prasenjit.sanyal14@gmail.com

Sujit Kumar Dalui

sujit_dalui@rediffmail.com

1 Department of Civil Engineering, Indian Institute of Engineering Science and Technology, Shibpur, Howrah, India for providing good ventilation. In a housing complex, it can be used as a shared park-like space, parking garage or swimming pool. Wind effects of conventional plan shape building are given in relevant wind standards such as Australian/ NewZealand AS/NZS 1170.2: 2011, British BS 6399-2: 1997, American code ASCE 7-16 and Indian IS: 875 (Part3), 2015.

However, these international standards are silent about the wind effects on the building when there is an inner courtyard. Windward face generally experiences critical pressure distribution for conventional plan shape model, but unconventional or irregular plan shaped buildings sometimes experience critical pressure distribution on other faces also. Responses of unconventional plan shaped buildings to the wind are estimated by employing CFD or wind tunnel techniques. Some researchers in the field of wind engineering conducted works on unconventional plan shape high rise buildings. Gomes et al. (2005) experimentally and analytically calculated wind pressure on different faces of ' $U$ ' and ' $\mathrm{L}$ ' plan shaped tall buildings. Wind pressure distribution on various faces was observed to be different from that of a square model. Amin and Ahuja (2011) presented experimental results of pressure distribution on various faces of ' $T$ ' and ' $L$ ' plan shape tall buildings for various wind incidence 
angles. It was observed that pressure distribution around these tall buildings largely depends on the plan shape. $\mathrm{Fu}$ et al. (2008) presented field measurement data of boundary layer wind characteristics over typical open country and urban terrain for two super tall buildings. Results of fullscale measurement were compared with wind tunnel data. Ramponi and Blocken (2012) calculated outdoor and indoor air flows of a building under natural cross ventilation strategies. Montazeri and Blocken (2013) compared the wind effects on buildings with and without balconies. Experimental investigation on aerodynamic characteristics of various triangular shaped tall buildings was done by Kumar et al. (2013). Raj and Ahuja (2013) compared the base shear, base moment and twisting moment of three rigid building models having the same floor area, but different cross-sectional shapes by changing the wind incidence angle. Muehleisen and Patrizi (2013) compared a huge set of data and derived a parametric equation of $C_{\mathrm{p}}$. Bhattacharyya et al. (2014) presented analytical and experimental results of pressure distribution on various faces of ' $E$ ' plan shape tall buildings for various wind incidence angles. Experimental and analytical results of pressure distribution on various faces of ' $\mathrm{Y}$ ' shape tall buildings were presented by Mukherjee et al. (2014). Peculiar pressure distribution has been observed on certain face due to self-interference effect. Chakraborty et al. (2014) presented numerical and experimental study of ' + ' shaped tall building for $0^{\circ}$ and $45^{\circ}$ angles of wind attack. The inter-building and intra-building aerodynamic behaviours of linked buildings were investigated by Song et al. (2016). Paul and Dalui (2016) calculated the Wind effects on ' $Z$ ' plan shaped tall building by changing the wind incidence angle from $0^{\circ}$ to $150^{\circ}$ at an interval of $30^{\circ}$. The flow and dispersion in cross-ventilated isolated buildings by changing the opening positions were analysed by Tominaga and Blocken (2016).

Very little research has been done on wind effects of opening on tall buildings till now. Furthermore, the Wind Codes do not provide any guidelines for inner courtyard, which necessitates research on this area. The current work mainly focuses on wind effects of courtyard and opening on rectangular plan shaped tall building with inner courtyard for $0^{\circ}-180^{\circ}$ wind incidence angle at an interval of $30^{\circ}$.

\section{Numerical analysis of the tall building by ANSYS CFX}

In the present study, the rectangular plan shaped building with opening and inner courtyard is analysed by the CFD package, namely ANSYS CFX (version 16.0). The boundary layer wind profile is governed by the power law equation: $U(z)=U_{0}\left(Z / Z_{0}\right)^{\alpha}$

Where $U(z)$ is velocity at some particular height $Z, U_{0}$ is boundary layer velocity, $Z_{0}$ is the boundary layer depth and $\alpha$ is power law exponent and its value is taken as 0.133 which satisfies terrain category II, mentioned in IS 875-part 3 (2015).

\section{Details of model}

The buildings are modelled in 1:300 scale and the wind velocity scale is taken as 1:5. So as per the recommendation of IS 875-part 3 (2015), the scaled down velocity of Kolkata zone is taken as $10 \mathrm{~m} / \mathrm{s}$. $k-\varepsilon$ turbulence model is used for the numerical simulation. The $k-\varepsilon$ models use the gradient diffusion hypothesis to relate Reynolds stresses to mean velocity gradients and turbulent viscosity. Turbulent viscosity is modelled as the product of turbulent length scale and turbulent velocity. $k$ is the turbulent kinetic energy and is defined as the variance of fluctuations in velocity. It has dimensions of $\mathrm{L}^{2} \mathrm{~T}^{-2} \cdot \epsilon$ is the turbulence eddy dissipation which is actually the rate at which the velocity fluctuation dissipates and has dimensions of per unit time.

The continuity and momentum equations are

$\frac{\partial \rho}{\partial t}+\frac{\partial\left(\rho U_{j}\right)}{\partial x_{j}}=0$

$\frac{\partial \rho U_{i}}{\partial t}+\frac{\partial\left(\rho U_{i} U_{j}\right)}{\partial x_{j}}=-\frac{\partial P^{\prime}}{\partial x_{i}}+\frac{\partial}{\partial x_{j}}\left[\mu_{\mathrm{eff}}\left(\frac{\partial U_{i}}{\partial x_{j}}+\frac{\partial U_{j}}{\partial x_{i}}\right)\right]+S_{\mathrm{M}}$,

where $S_{M}$ is the sum of body forces, $\mu_{\text {eff }}$ is the effective viscosity accounting for turbulence and $P^{\prime}$ is the modified pressure. Density and velocity are denoted by $\rho$ and $U . i$ and $j$ are two mutually perpendicular directions.

The $k-\varepsilon$ model is based on the concept of eddy viscosity, so that

$\mu_{\text {eff }}=\mu+\mu_{t}$,

where $\mu_{t}$ is turbulent viscosity

$\mu_{t}=C_{\mu} \rho \frac{k^{2}}{\epsilon}$.

The values of $k$ and $\epsilon$ come from the differential transport equations of turbulence kinetic energy and turbulence dissipation rate

$\frac{\partial(\rho k)}{\partial t}+\frac{\partial\left(\rho k U_{j}\right)}{\partial x_{j}}=\frac{\partial}{\partial x_{j}}\left[\left(\mu+\frac{\mu_{t}}{\sigma_{k}}\right) \frac{\partial k}{\partial x_{j}}\right]+P_{\mathrm{k}}+P_{\mathrm{b}}-\rho \epsilon-Y_{\mathrm{M}}+S_{\mathrm{k}}$ 
$\frac{\partial(\rho \epsilon)}{\partial t}+\frac{\partial\left(\rho \epsilon U_{j}\right)}{\partial x_{j}}=\frac{\partial}{\partial x_{j}}\left[\left(\mu+\frac{\mu_{t}}{\sigma_{j}}\right) \frac{\partial \epsilon}{\partial x_{j}}\right]+\rho C_{1} S_{\epsilon}-\rho C_{2} \frac{\epsilon^{2}}{k+\sqrt{v \varepsilon}}+C_{1} \frac{\epsilon}{k} C_{3 \epsilon} P_{\mathrm{b}}+S_{\epsilon}$,

where $P_{\mathrm{k}}$ represents the generation of turbulence kinetic energy due to the mean velocity gradients, $P_{\mathrm{b}}$ represents the generation due to buoyancy, $Y_{m}$ represents the contribution of fluctuating dilatation in compressible turbulence to overall dissipation rate and $C_{1}$ and $C_{2}$ are constants. $\sigma_{k}$ and $\sigma_{\epsilon}$ are the turbulent Prandtl numbers for $k$ (turbulence kinetic energy) and $\epsilon$ (dissipation rate). The values considered for $C_{1 \epsilon}, \sigma_{k}$ and $\sigma_{\epsilon}$ are taken as $1.44,1$ and 1.3 , respectively, as per the recommendation of Jones and Launder (1972).

\section{Domain and meshing}

A domain has $5 \mathrm{H}, 15 \mathrm{H}, 5 \mathrm{H}$ and $5 \mathrm{H}$ inlet, outlet, two side face and top clearances from edges of the buildings, where $\mathrm{H}$ is the height of the model as shown in Fig. 1. This domain is constructed as per recommendation of Franke et al. (2004). Such a large domain is good enough for vortex generation

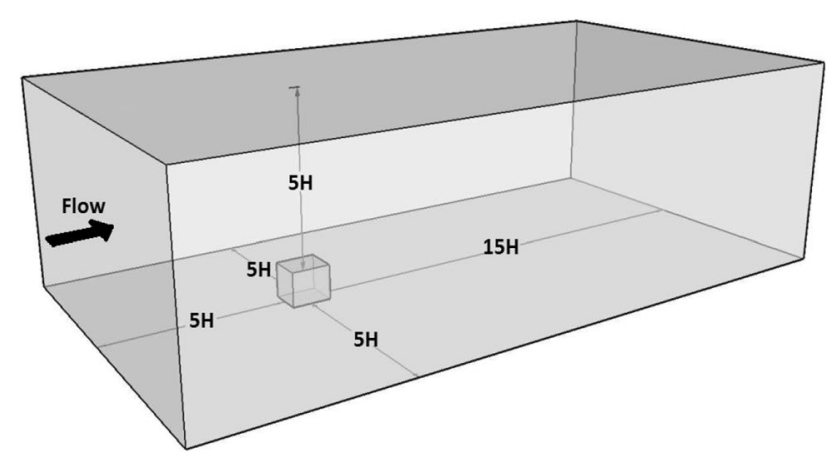

Fig. 1 Domain used for CFD simulation on the leeward side and avoids backflow of wind. Moreover, no blockage correction is required. Meshing the domain is done by tetrahedral elements (Fig. 2). The mesh near the building is made more fine compared to other location for accurately checking the wind parameters. The mesh inflation is provided near the boundaries to provide a smooth flow.

The velocity of wind at inlet is taken as $10 \mathrm{~m} / \mathrm{s}$. No slip wall is considered at building faces and the bottom, and free slip wall is considered for the top and side faces of the domain. The relative pressure at outlet is taken as $0 \mathrm{~Pa}$. The operating pressure in the domain is $1 \mathrm{~atm}$, i.e. $101,325 \mathrm{~Pa}$.

\section{Validation}

Before starting the numerical wind analysis of the building with inner courtyard and opening, the results from the ANSYS CFX package are to be validated. For this reason, a square plan shaped building (Fig. 3) of dimension $100 \mathrm{~mm} \times 150 \mathrm{~mm}$ and height $700 \mathrm{~mm}$ is analysed in the afore-mentioned domain by $k-\varepsilon$ and SST turbulence model for $0^{\circ}$ wind incidence angle using ANSYS CFX. The free

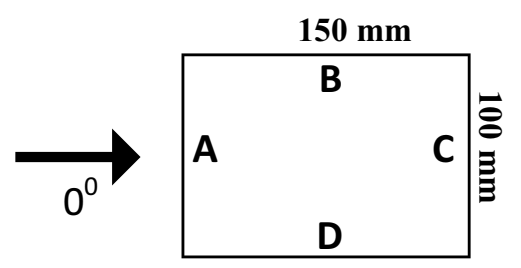

Fig. 3 Different faces of model with the direction of wind

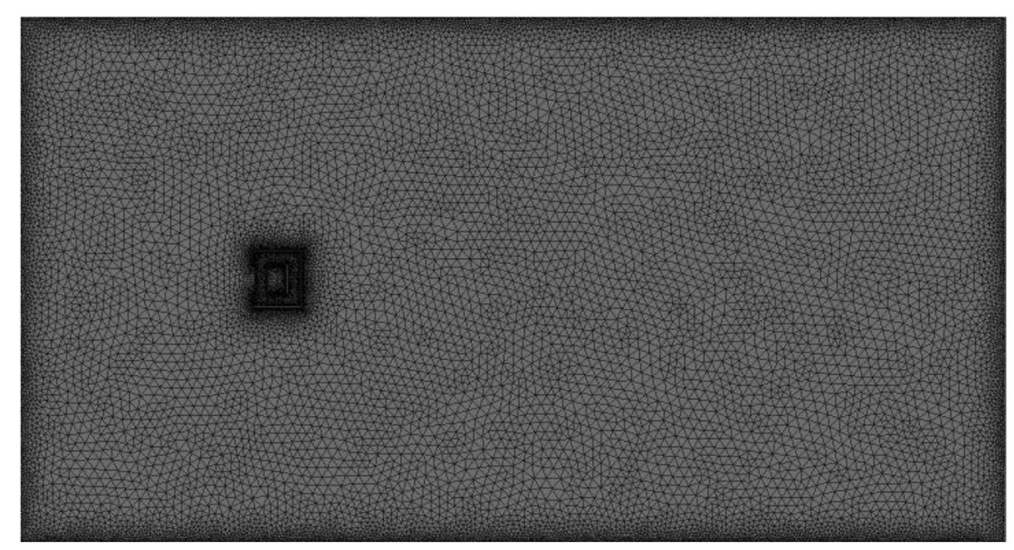

(a)

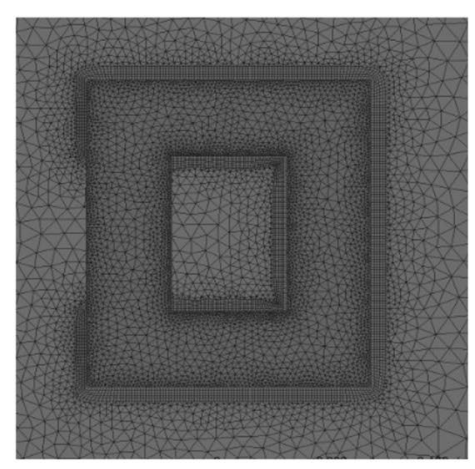

(b)

Fig. 2 a Typical mesh pattern in the computational domain. b Zoom-in view around the building mode 
stream velocity $10 \mathrm{~m} / \mathrm{s}$ is considered at the inlet. The domain is constructed as per recommendation of Franke et al. (2004) as mentioned earlier. The face average values of coefficient of pressures are determined by ANSYS CFX package and compared with different international wind codes.

The external pressure coefficient ' $C_{\mathrm{p}}$ ' is calculated using the formula $C_{\mathrm{p}}=P /\left(0.6 \mathrm{~V}_{\mathrm{z}}^{2}\right)$, where $P$ is the wind pressure and $V_{z}$ is the design wind speed. The external surface pressure coefficients, $C_{\mathrm{p}}$ (face average value), for different faces of the model are listed and compared with different international standards as shown in Fig. 4.

To correlate the results obtained from the two models with those from experimental studies in the literature, a comparison is made between present and Sarath et al. (2015) results. Eventually, dimensions and all other parameters related to the wind flow are matched with the numerical studies. For better understanding between two turbulence models and experimental results, the pressure coefficients along the horizontal centrelines around the building periphery for $0^{\circ}$ wind incidence angle are compared.

From Fig. 4, it can be seen that results found by the both turbulence models are approximately the same with the values mentioned in different IS codes. From Fig. 5, it is observed that the horizontal centrelines obtained from $k-\varepsilon$ model have a better agreement with the experimental results compared to those from SST model. So, further analysis has been done based on $k-\varepsilon$ turbulence model.

\section{Parametric study}

The building is modelled in 1:300 scale. The scaled down dimension of the building is $600 \mathrm{~mm} \times 500 \mathrm{~mm} \times 500 \mathrm{~mm}$. The isometric views of different cases are shown in Fig. 6.

The numerical simulation of each building is also carried out by changing the wind incidence angle $\theta$ from $0^{\circ}$ to $180^{\circ}$ at an interval of $30^{\circ}$. Height of opening of Model $\mathrm{C}$ varies from 0 to $500 \mathrm{~mm}$.

At $500 \mathrm{~mm}$ opening, it simply becomes a $\mathrm{U}$ plan shaped tall building.

The top view and bottom view with wind incidence angles of Model C are shown in Fig. 7. The faces shown in these plan views are sufficient enough for explaining different faces of all the models.

Fig. 4 Comparison of mean pressure coefficient between numerical results and different international standards
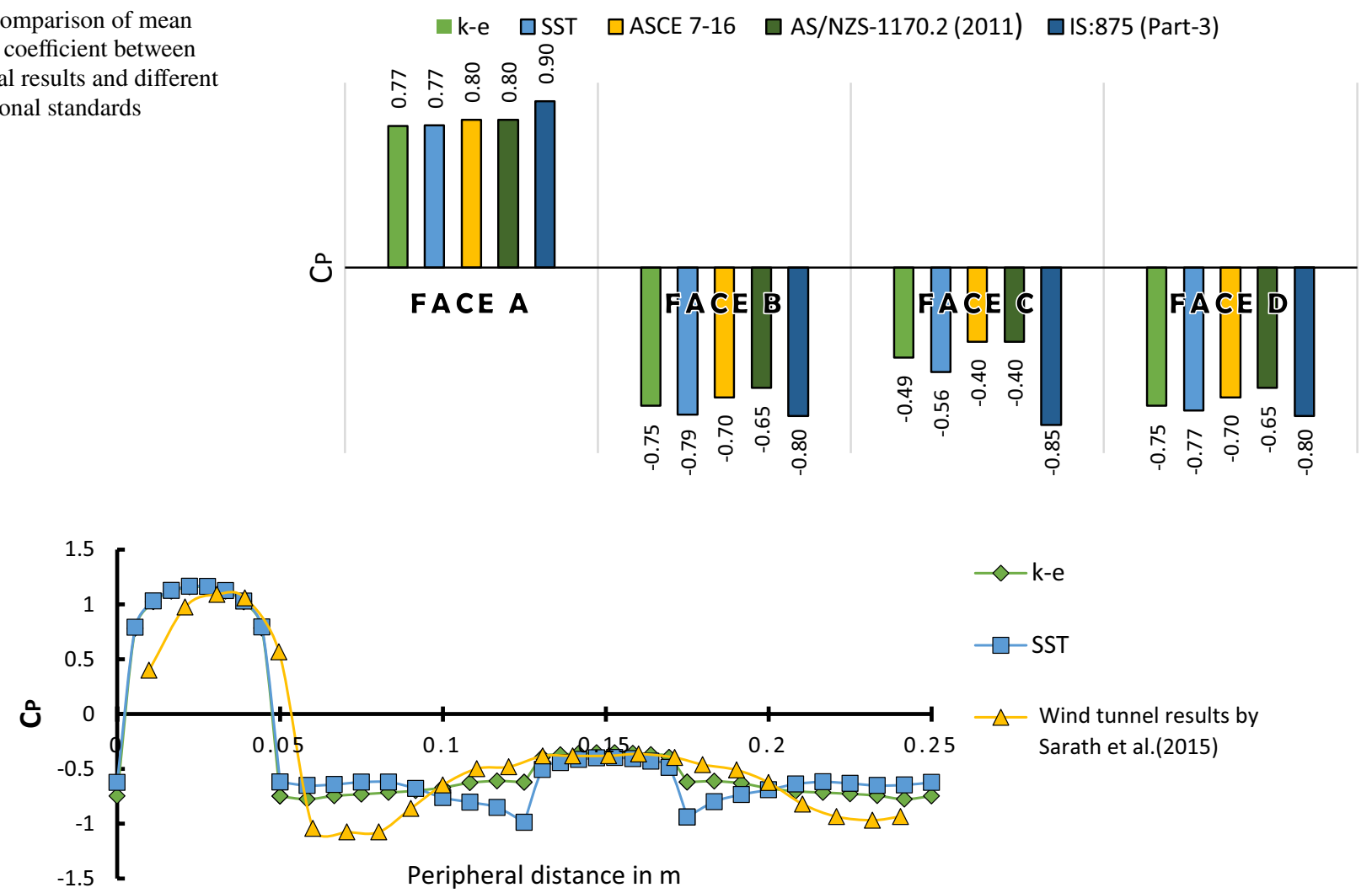

Fig. 5 Comparison of pressure coefficients around the building at mid depth for $k$ - $\varepsilon$ model, SST model and experimental results by Sarath et al. (2015) for $0^{\circ}$ wind incidence angle 


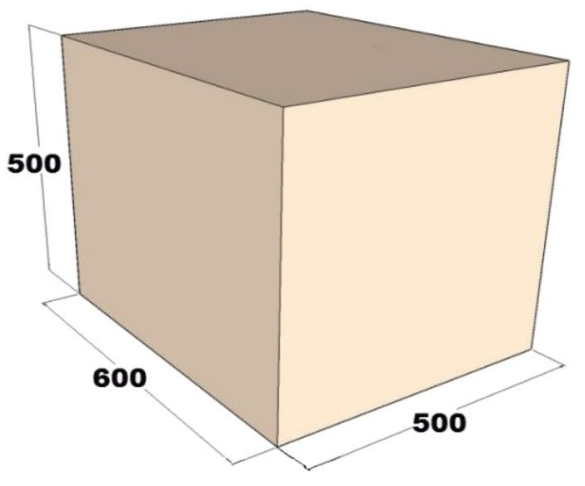

(a) MODEL A : Building without courtyard

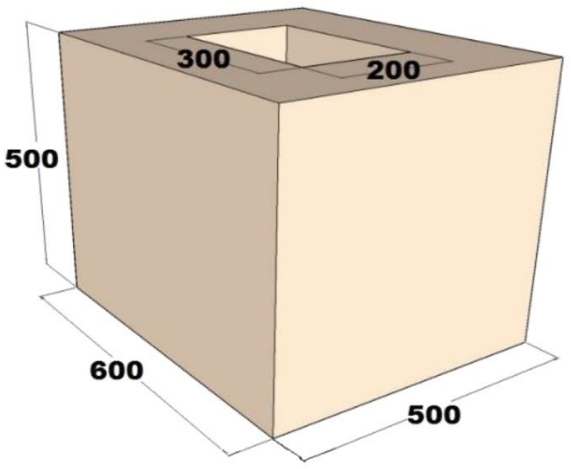

(b) MODEL B : Building with courtyard (No opening)

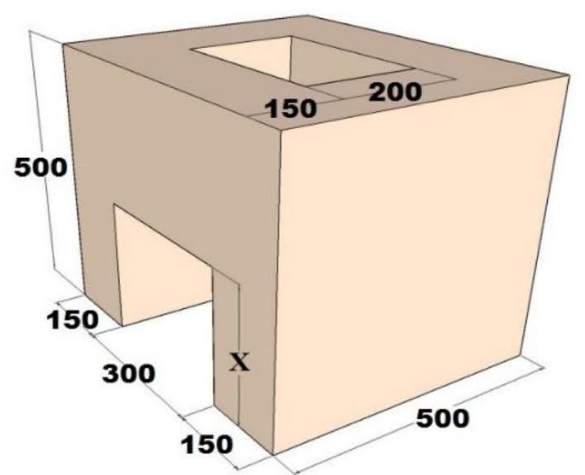

(c) MODEL $\mathrm{C}$ : Building with courtyard (Opening Depth $\mathrm{X}: 0<\mathrm{X} \leq 500$ )

Fig. 6 Isometric view of different cases (all dimensions are in $\mathrm{mm}$

\section{Results and discussion}

\section{Numerically predicted wind flow}

Flow patterns of each building for different wind incidence angles are shown in Fig. 8. For $0^{\circ}$ wind incidence angle,

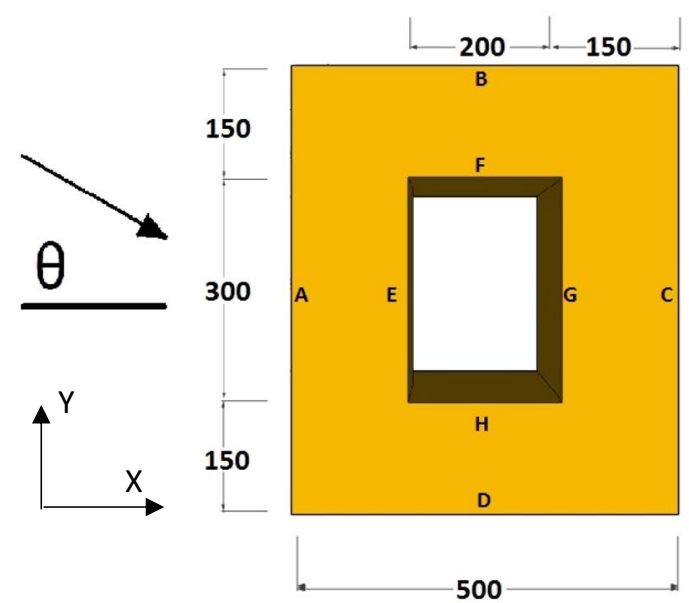

(a) Top view

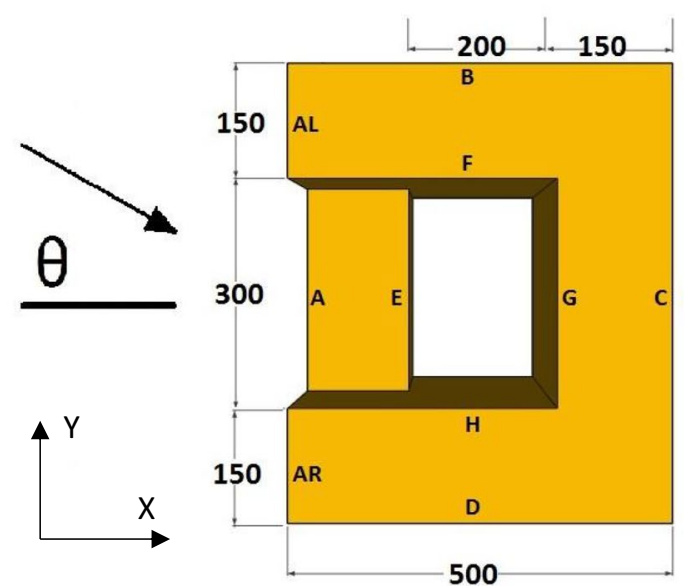

(b) Bottom View

Fig. 7 Wind incidence angle $(\theta)$ with respect to plan [Model C]; $0 \leq \theta \leq 180^{\circ}$

the flowlines are symmetrical till the generation of vortices. Wind flow separates after colliding with the windward Face A. So, it mainly experiences positive pressure with slight negative pressure near the edges due to flow separation. Faces B and D experience negative pressure due to side wash. Two almost symmetrical vortices are formed in the wake region behind Face $\mathrm{C}$. Unlike Model B, wind directly enters inside the courtyard from the opening for Model C, which causes change in pressure of the inner faces. For different angles of attack, Models A and B follow almost the same type of flow pattern. With the increase in angle of attack, different faces change their position with respect to the windward direction and cause a huge change in pressure effects of these faces. For some cases, vortex is also formed inside the courtyard of Model C. 


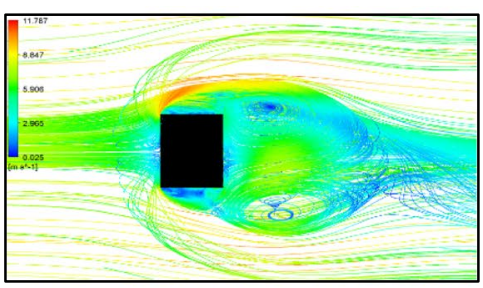

(a) Flow around model $\mathrm{A}\left(\theta=0^{\circ}\right)$

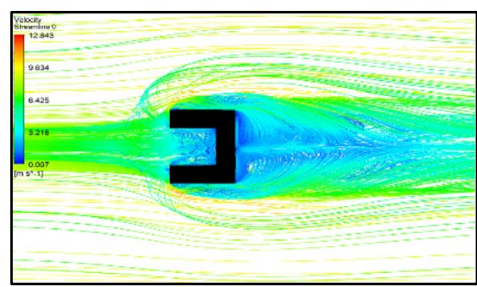

(d) Flow around model $\mathrm{C} ; \mathrm{x}=0.5 \mathrm{~m}$ $\left(\theta=0^{\circ}\right)$

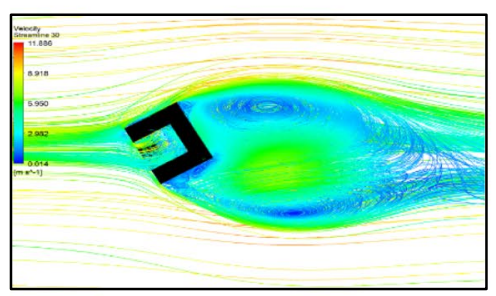

(g) Flow around model $\mathrm{C}$; $\mathrm{x}=0.25 \mathrm{~m}\left(\theta=30^{\circ}\right)$

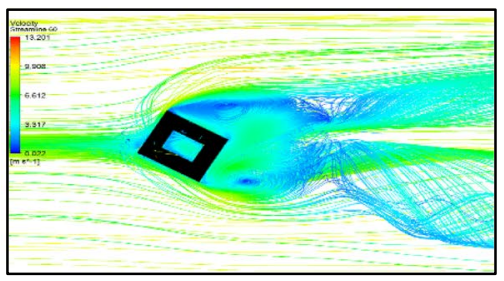

(j) Flow around model $\mathrm{B}\left(\theta=60^{\circ}\right)$

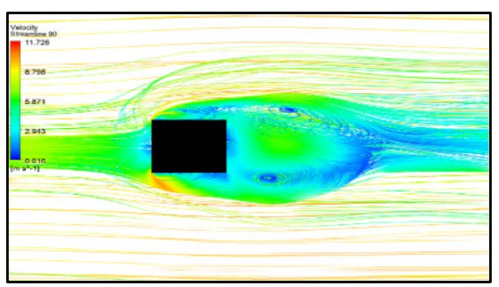

(m) Flow around model A $(\theta=$ $90^{\circ}$ )

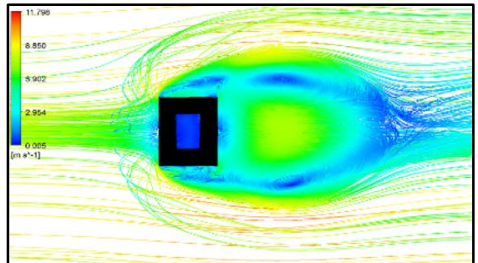

(b) Flow around model $\mathrm{B}\left(\theta=0^{\circ}\right)$

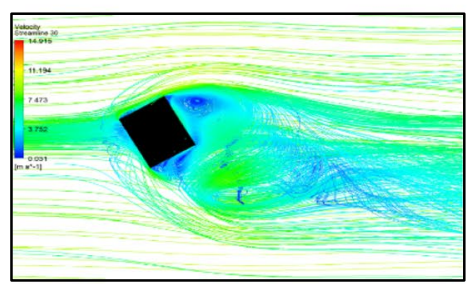

(e) Flow around model A $(\theta=$ $30^{\circ}$ )

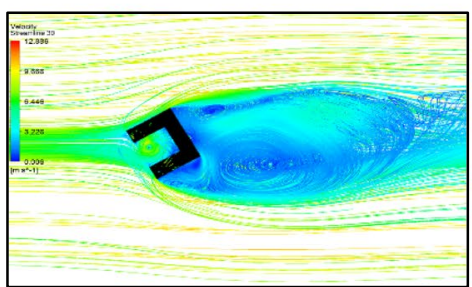

(h) Flow around model $\mathrm{C} ; \mathrm{x}=0.5 \mathrm{~m}$ $\left(\theta=30^{\circ}\right)$

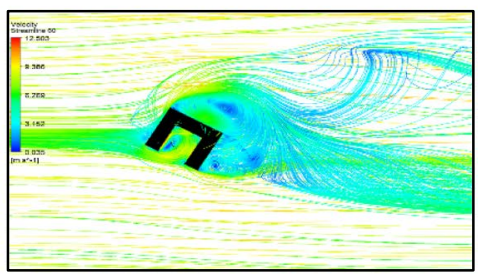

(k) Flow around model $\mathrm{C}$; $\mathrm{x}=0.25 \mathrm{~m}$ $\left(\theta=60^{\circ}\right)$

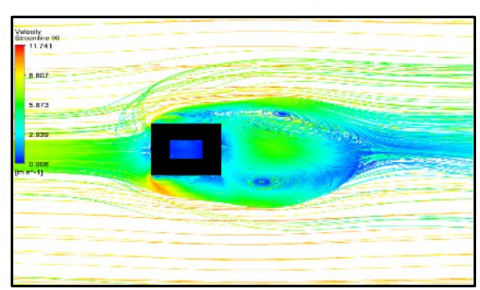

(n) Flow around modelB $\left(\theta=90^{\circ}\right)$

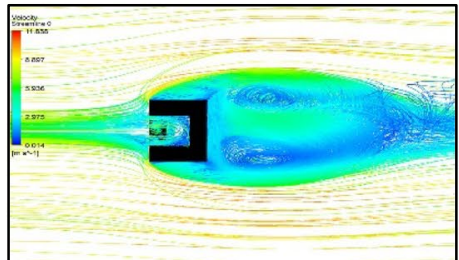

(c) Flow around model $\mathrm{C}$; $\mathrm{x}=0.25 \mathrm{~m}\left(\theta=0^{\circ}\right)$

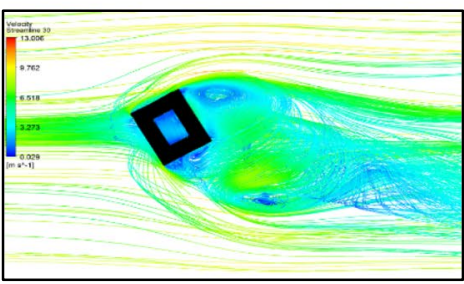

(f) Flow around model $\mathrm{B}\left(\theta=30^{\circ}\right)$

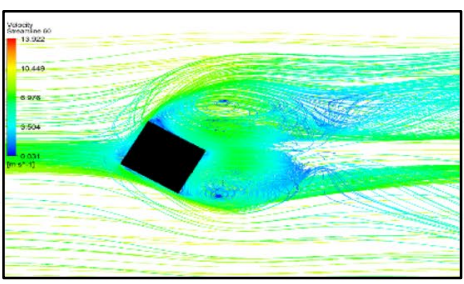

(i) Flow around model $\mathrm{A}\left(\theta=60^{\circ}\right)$

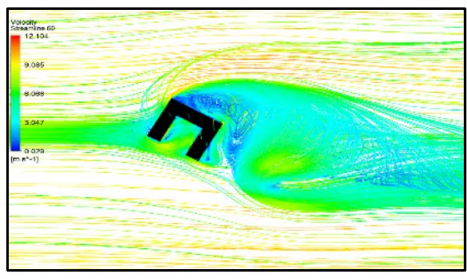

(l) Flow around model $\mathrm{C}$; $\mathrm{x}=0.5 \mathrm{~m}$ $\left(\theta=60^{\circ}\right)$

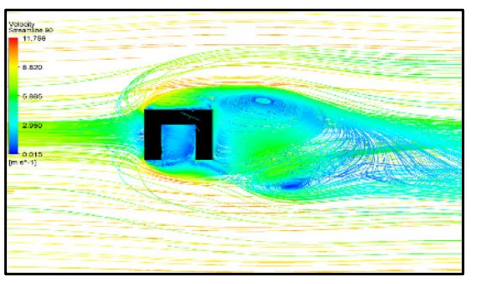

(o) Flow around model $\mathrm{C} ; \mathrm{x}=0.25 \mathrm{~m}$ $\left(\theta=90^{\circ}\right)$

Fig. 8 Bottom view of 3D flow pattern around different models for different wind incidence angles 


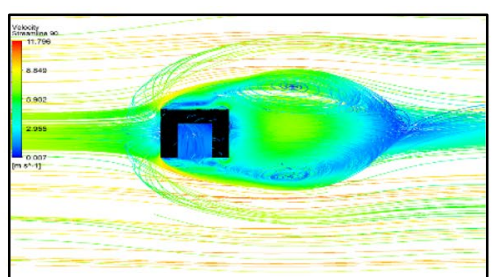

(p) Flow around model $\mathrm{C} ; \mathrm{x}=0.5 \mathrm{~m}$ $\left(\theta=90^{\circ}\right)$

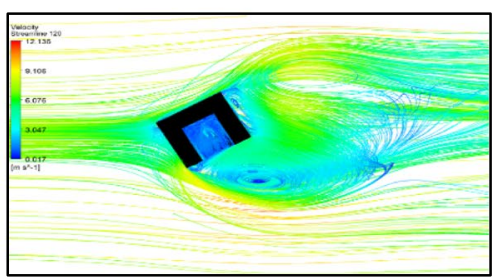

(s) Flow around model $\mathrm{C} ; \mathrm{x}=0.25 \mathrm{~m}$ $\left(\theta=120^{\circ}\right)$

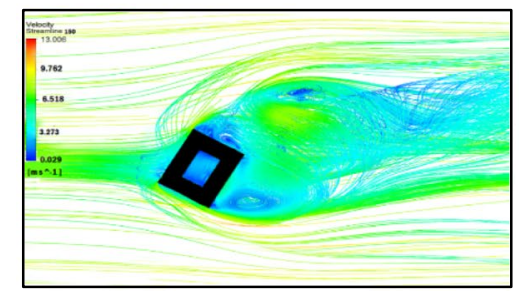

(v) Flow around model $\mathrm{B}(\theta=$ $\left.150^{\circ}\right)$

Fig. 8 (continued)

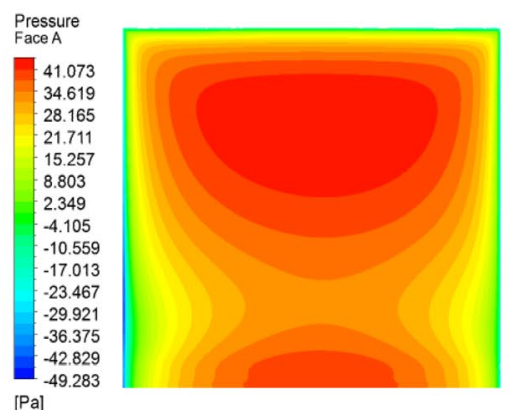

(a)

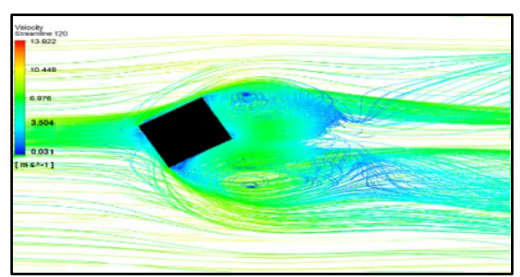

(q) Flow around model $\mathrm{A}\left(\theta=120^{\circ}\right)$

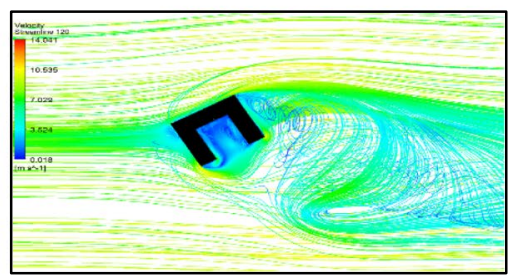

(t) Flow around model $\mathrm{C} ; \mathrm{x}=0.5 \mathrm{~m}$ $\left(\theta=120^{\circ}\right)$

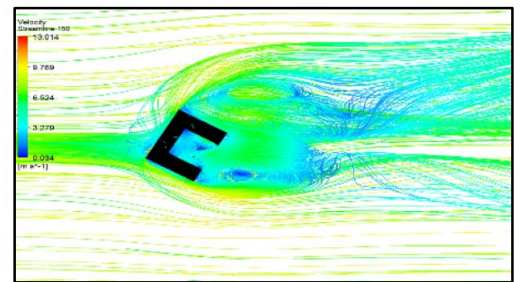

(w) Flow around model $\mathrm{C}$; $\mathrm{x}=0.25 \mathrm{~m}$ $\left(\theta=150^{\circ}\right)$

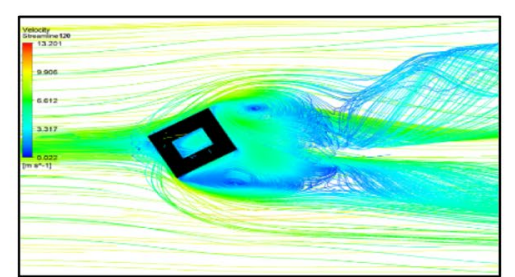

(r) Flow around model $\mathrm{B}\left(\theta=120^{\circ}\right)$

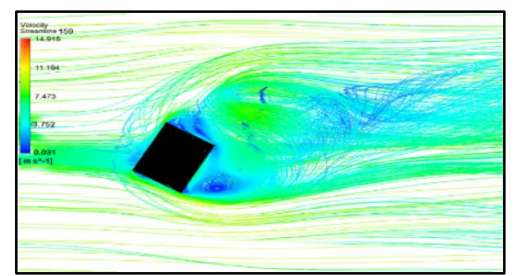

(u) Flow around model $\mathrm{A}(\theta=$ $\left.150^{\circ}\right)$

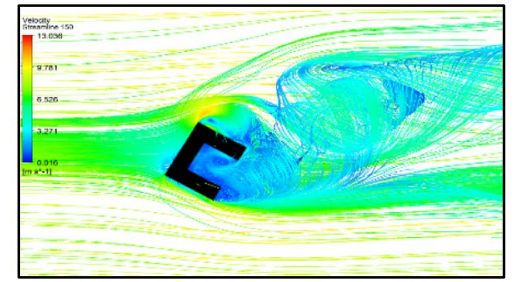

(x) Flow around model $\mathrm{C}$; $\mathrm{x}=0.5 \mathrm{~m}$ $\left(\theta=150^{\circ}\right)$

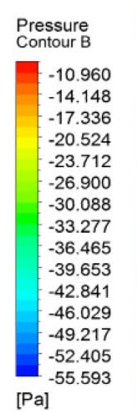

[Pa]

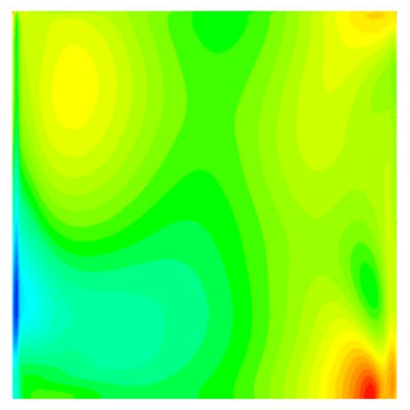

(b)

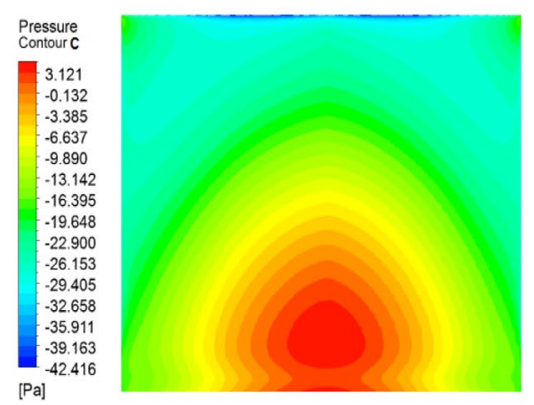

(c)

Fig. 9 Pressure contour of different faces of Model A $\left[\theta=0^{\circ}\right]$. a Face A. b Faces B and D. c Face C

\section{Pressure distribution}

For $0^{\circ}$ wind incidence angle, each model experiences symmetrical flow pattern till the vortices are formed. Thus, symmetrical faces will experience identical or almost similar pressure distribution; so only six Faces A, B, C, E, F and G are sufficient for understanding the behaviour of every model under wind action for $\theta=0^{\circ}$. Pressure contours of every plane for some particular cases at $0^{\circ}$ wind angle are shown in Figs. 9, 10, 11 and 12.

The key features of the pressure contours on various surfaces of different models are described as follows: Models 


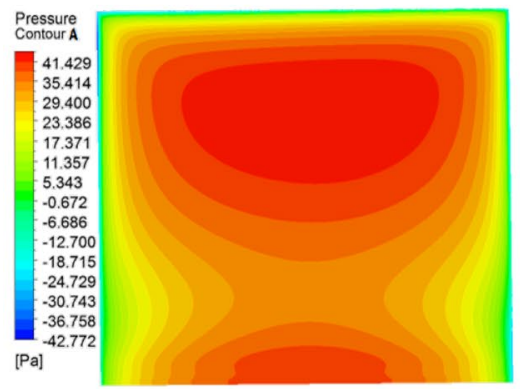

(a)

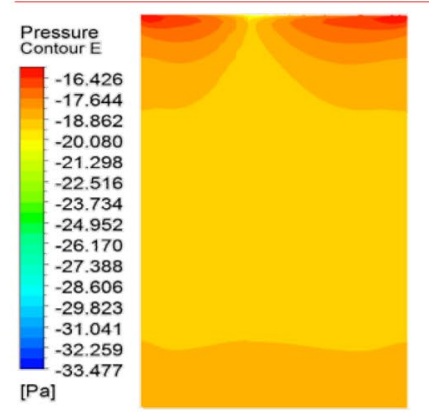

(d)

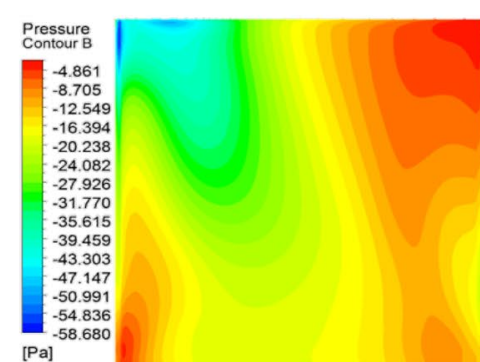

(b)

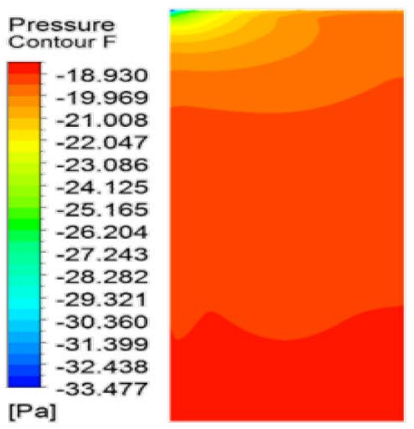

(e)

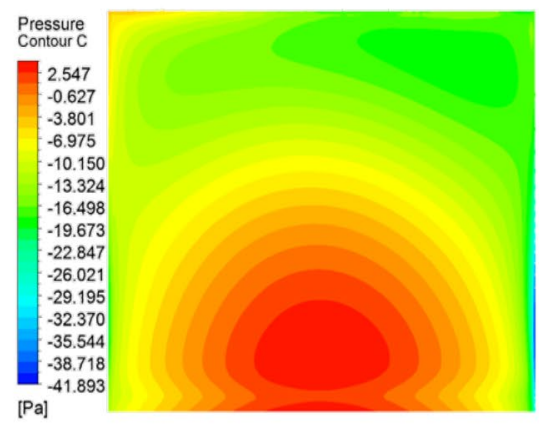

(c)

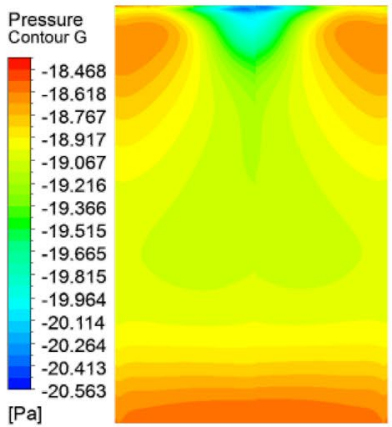

(f)

Fig. 10 Pressure contour of different faces of Model B $\left[\theta=0^{\circ}\right]$. a Face A. b Faces B and D. c Face C. d Face E. e Faces F and H. f Face G

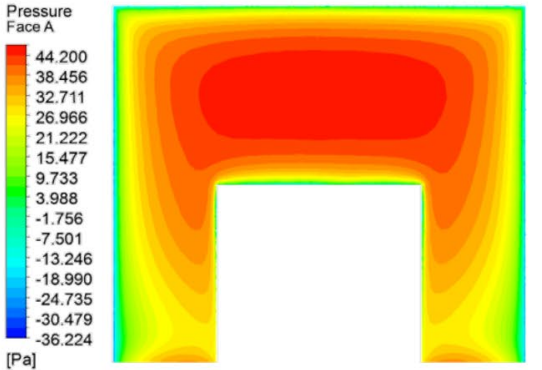

(a)

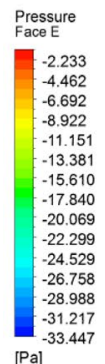

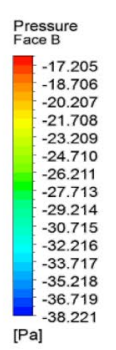

[Pa] -38.221

(b)

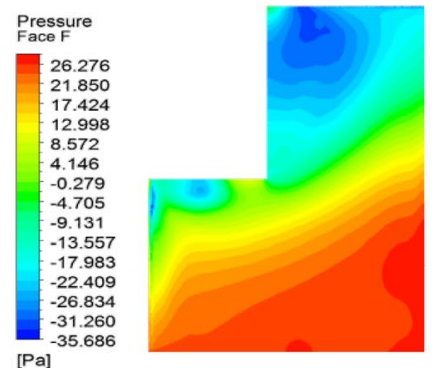

(e)

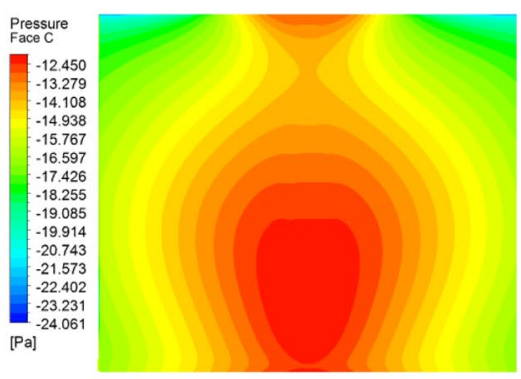

(c)

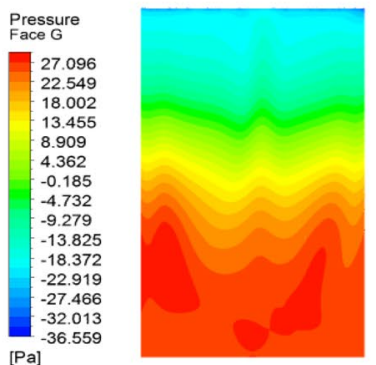

(f)

Fig. 11 Pressure contour of different faces of Model C $(X=0.25 \mathrm{~m})\left[\theta=0^{\circ}\right]$. a Face A. b Faces B and D. c Face C. d Face E. e Faces F and H. f Face $\mathrm{G}$ 


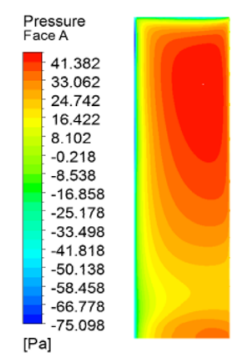

(a)

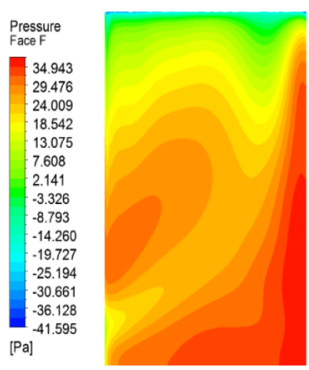

(d)

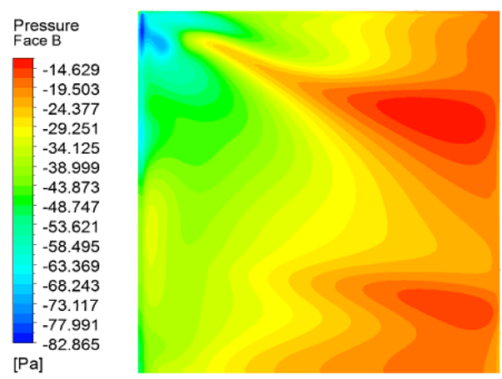

(b)

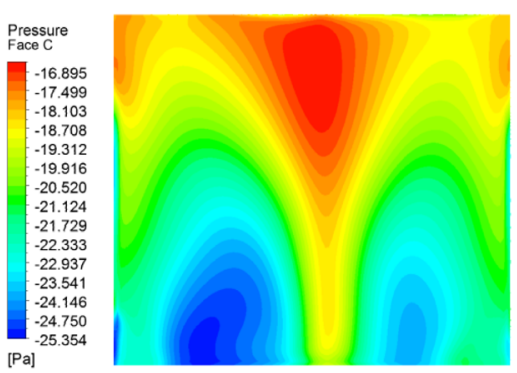

(c)

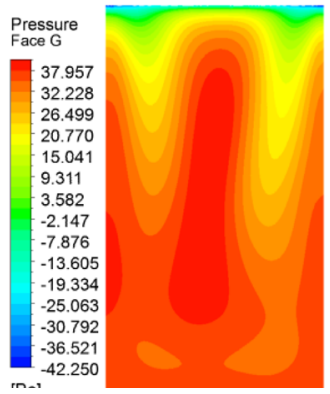

(e)

Fig. 12 Pressure contour of different faces of Model C $(X=0.5 \mathrm{~m})\left[\theta=0^{\circ}\right]$. a Face A. b Faces B and D. c Face C. d Faces F and H. e Face G

A and B experience similar type of pressure distribution for windward and leeward face. Only side faces observed some discrepancy due to the difference in the formation of vortices. Face A experiences mainly positive pressure except near the edges. Pressure distribution is parabolic in nature due to boundary layer flow and symmetrical about vertical centreline. Faces B and D have throughout negative pressure with less negative value towards the leeward side due to some reattachment of wind.

Face $\mathrm{C}$ has slightly positive pressure near the bottom and negative elsewhere. The negative pressure is due to the formation of vortex, and slight positive pressure at the bottom is because the reattachment wind pressure is higher than the suction pressure. Inner courtyard Faces E, F and $\mathrm{H}$ have throughout negative pressure. Face $\mathrm{G}$ has lower negative pressure at bottom and higher negative pressure towards top. For $\theta=0^{\circ}$, Faces A, B, C and $\mathrm{E}$ do not experience much variation in pressure for different models. Faces F, G and $\mathrm{H}$ have negative value at top and positive value at bottom. With the increase in area of opening these faces experience high increase in pressure at bottom of its surface.

\section{Pressure and force coefficient}

- The mean pressure coefficient for all surfaces of Models A, B and C is tabulated in Table 1. Maximum positive mean pressure coefficient of 0.813 occurs on Face
A of Model A when the wind incidence angle is $0^{\circ}$, and maximum negative mean pressure coefficient of -0.848 occurs on Face $\mathrm{E}$ of Model $\mathrm{C}(x=0.25 \mathrm{~m})$ at angle of attack $60^{\circ}$. For $0^{\circ}$, wind angle symmetrical faces experience almost the same pressure distribution. At the same wind angle, the variation of $C_{\mathrm{p}}$ for different heights of opening is not very significant for Faces A, B, C, D and E. But for Faces $\mathrm{F}, \mathrm{G}$ and $\mathrm{H}$ the variation is very high for wind angle $0^{\circ}, 30^{\circ}$ and $60^{\circ}$. So, for these wind angles more cases of opening are considered. With the increase in opening, the $C_{\mathrm{p}}$ value for Faces $\mathrm{F}, \mathrm{G}$ and $\mathrm{H}$ increases invariably. The variation of $C_{\mathrm{p}}$ value for different wind angles is more for the outer faces than the inner faces.

In the context of detail study on wind pressure coefficients of each of the faces, the variation of $C_{\mathrm{p}}$ with wind incidence angles and openings are required to plot. Also, it is important to quantify the mean pressure coefficients for a particular face of different models without rigorous calculation. For that reason, it is of utter importance to propose analytical expression of $C_{\mathrm{p}}$ for all the faces.

$C_{\mathrm{p}}$ of different faces for Models $\mathrm{A}$ and $\mathrm{B}$ are plotted in Fig. 13 as scattered points. These data are then fitted as a fifth degree polynomial, $C_{\mathrm{p}}=\alpha_{0}+\alpha_{1} \theta+\alpha_{2} \theta^{2}+\alpha_{3} \theta^{3}+\alpha_{4} \theta^{4}+\alpha_{5} \theta^{5} \quad$ by least squares regression method using the method as discussed in Appendix. Where $\theta$ is the angle of attack and varies from 
Table 1 Mean pressure coefficients for each faces of different building models for various wind angles

\begin{tabular}{|c|c|c|c|c|c|c|c|c|c|}
\hline$\theta$ & Model & Face A & Face B & Face $\mathrm{C}$ & Face D & Face E & Face F & Face $\mathrm{G}$ & Face $\mathrm{H}$ \\
\hline \multirow[t]{8}{*}{$0^{\circ}$} & Model A & 0.813 & -0.624 & -0.391 & -0.624 & & & & \\
\hline & Model B & 0.800 & -0.461 & -0.204 & -0.461 & -0.456 & -0.459 & -0.456 & -0.459 \\
\hline & Model C $(X=0.1 \mathrm{~m})$ & 0.564 & -0.578 & -0.364 & -0.438 & -0.450 & -0.344 & -0.126 & -0.344 \\
\hline & Model C $(X=0.2 \mathrm{~m})$ & 0.619 & -0.528 & -0.383 & -0.528 & -0.488 & -0.049 & 0.139 & -0.049 \\
\hline & Model C $(X=0.25 \mathrm{~m})$ & 0.651 & -0.493 & -0.376 & -0.563 & -0.591 & 0.008 & 0.217 & 0.008 \\
\hline & Model C $(X=0.3 \mathrm{~m})$ & 0.658 & -0.468 & -0.369 & -0.598 & -0.534 & 0.186 & 0.388 & 0.186 \\
\hline & Model C $(X=0.4 \mathrm{~m})$ & 0.661 & -0.657 & -0.434 & -0.675 & -0.432 & 0.425 & 0.714 & 0.425 \\
\hline & Model C $(X=0.5 \mathrm{~m})$ & 0.664 & -0.691 & -0.473 & -0.691 & - & 0.539 & 0.715 & 0.539 \\
\hline \multirow[t]{8}{*}{$30^{\circ}$} & Model A & 0.646 & -0.146 & -0.748 & -0.398 & & & & \\
\hline & Model B & 0.641 & 0.015 & -0.655 & -0.322 & -0.659 & -0.650 & -0.639 & -0.643 \\
\hline & Model C $(X=0.1 \mathrm{~m})$ & 0.397 & 0.031 & -0.553 & -0.388 & -0.288 & -0.185 & -0.047 & -0.073 \\
\hline & Model C $(X=0.2 \mathrm{~m})$ & 0.407 & 0.050 & -0.543 & -0.372 & -0.345 & 0.019 & 0.187 & 0.156 \\
\hline & Model C $(X=0.25 \mathrm{~m})$ & 0.422 & 0.069 & -0.515 & -0.450 & -0.445 & 0.190 & 0.260 & 0.250 \\
\hline & Model C $(X=0.3 \mathrm{~m})$ & 0.432 & 0.089 & -0.500 & -0.478 & -0.373 & 0.420 & 0.411 & 0.437 \\
\hline & Model C $(X=0.4 \mathrm{~m})$ & 0.509 & 0.129 & -0.461 & -0.538 & -0.308 & 0.515 & 0.548 & 0.483 \\
\hline & Model C $(X=0.5 \mathrm{~m})$ & 0.567 & 0.133 & -0.455 & -0.525 & - & 0.311 & 0.628 & 0.559 \\
\hline \multirow[t]{8}{*}{$60^{\circ}$} & Model A & -0.014 & 0.684 & -0.484 & -0.419 & - & - & - & - \\
\hline & Model B & 0.094 & 0.621 & -0.514 & -0.366 & -0.529 & -0.598 & -0.578 & -0.538 \\
\hline & Model C $(X=0.1 \mathrm{~m})$ & -0.185 & 0.560 & -0.735 & -0.473 & -0.650 & -0.531 & -0.487 & -0.195 \\
\hline & Model C $(X=0.2 \mathrm{~m})$ & -0.128 & 0.602 & -0.684 & -0.434 & -0.794 & -0.433 & -0.362 & -0.094 \\
\hline & Model C $(X=0.25 \mathrm{~m})$ & -0.111 & 0.604 & -0.753 & -0.443 & -0.848 & -0.328 & -0.343 & -0.098 \\
\hline & Model C $(X=0.3 \mathrm{~m})$ & -0.076 & 0.598 & -0.755 & -0.446 & -0.779 & -0.176 & -0.214 & 0.049 \\
\hline & Model C $(X=0.4 \mathrm{~m})$ & -0.051 & 0.604 & -0.663 & -0.409 & -0.628 & -0.020 & -0.062 & 0.188 \\
\hline & Model C $(X=0.5 \mathrm{~m})$ & 0.017 & 0.542 & -0.632 & -0.385 & - & -0.108 & 0.167 & 0.122 \\
\hline \multirow[t]{4}{*}{$90^{\circ}$} & Model A & -0.654 & 0.783 & -0.654 & -0.545 & - & - & - & - \\
\hline & Model B & -0.536 & 0.776 & -0.536 & -0.412 & -0.493 & -0.486 & -0.493 & -0.491 \\
\hline & Model C $(X=0.25 \mathrm{~m})$ & -0.517 & 0.779 & -0.539 & -0.412 & -0.714 & -0.478 & -0.487 & -0.383 \\
\hline & Model C $(X=0.5 \mathrm{~m})$ & -0.514 & 0.756 & -0.352 & -0.363 & - & -0.389 & -0.313 & -0.278 \\
\hline \multirow[t]{4}{*}{$120^{\circ}$} & Model A & -0.484 & 0.684 & -0.014 & -0.419 & - & - & - & - \\
\hline & Model B & -0.514 & 0.621 & 0.074 & -0.366 & -0.578 & -0.598 & -0.592 & -0.538 \\
\hline & Model C $(X=0.25 \mathrm{~m})$ & -0.664 & 0.568 & 0.178 & -0.518 & -0.635 & -0.592 & -0.600 & -0.442 \\
\hline & Model C $(X=0.5 \mathrm{~m})$ & -0.669 & 0.560 & 0.039 & -0.492 & - & -0.424 & -0.364 & -0.351 \\
\hline \multirow[t]{4}{*}{$150^{\circ}$} & Model A & -0.748 & -0.146 & 0.646 & -0.398 & - & - & - & - \\
\hline & Model B & -0.655 & 0.015 & 0.641 & -0.322 & -0.639 & -0.650 & -0.659 & -0.643 \\
\hline & Model C $(X=0.25 \mathrm{~m})$ & -0.548 & 0.070 & 0.638 & -0.507 & -0.629 & -0.495 & -0.552 & -0.517 \\
\hline & Model C $(X=0.5 \mathrm{~m})$ & -0.658 & 0.040 & 0.583 & -0.588 & - & -0.511 & -0.487 & -0.491 \\
\hline \multirow[t]{4}{*}{$180^{\circ}$} & Model A & -0.391 & -0.624 & 0.813 & -0.624 & - & - & - & - \\
\hline & Model B & -0.204 & -0.461 & 0.800 & -0.461 & -0.456 & -0.459 & -0.456 & -0.459 \\
\hline & Model C $(X=0.25 \mathrm{~m})$ & -0.487 & -0.674 & 0.735 & -0.644 & -0.589 & -0.487 & -0.485 & -0.442 \\
\hline & Model C $(X=0.5 \mathrm{~m})$ & -0.447 & -0.619 & 0.711 & -0.689 & - & -0.376 & -0.365 & -0.417 \\
\hline
\end{tabular}

$0^{\circ}$ to $180^{\circ}$. The polynomial coefficients along with along the regression coefficients $\left(R^{2}\right)$ for different faces are shown in Table 2. It is found that most of the polynomials are fitted well with fifth degree least-squares polynomial. All $R^{2}$ values are greater than 0.9 which is very much acceptable to construct a model with least-squares regression polynomial. The fitted polynomials are then plotted alongside of $C_{\mathrm{p}}$ data points in Fig. 13. From fitted polynomials, it is found that the maximum positive pressure occurs at Face $\mathrm{A}$ for $\theta \approx 11^{\circ}$ and maximum negative pressure occurs at the same face for $\theta \approx 155^{\circ}$. For Models $\mathrm{A}$ and $\mathrm{B}$, significant pressure variation occurs only on outside Faces A, B and C. For different wind angles, change in pressure on the inner faces of Model $B$ is very small.

The external surface pressure coefficients, $C_{\mathrm{p}}$ (face average value), of different faces for Model $\mathrm{C}$ are fitted as a 


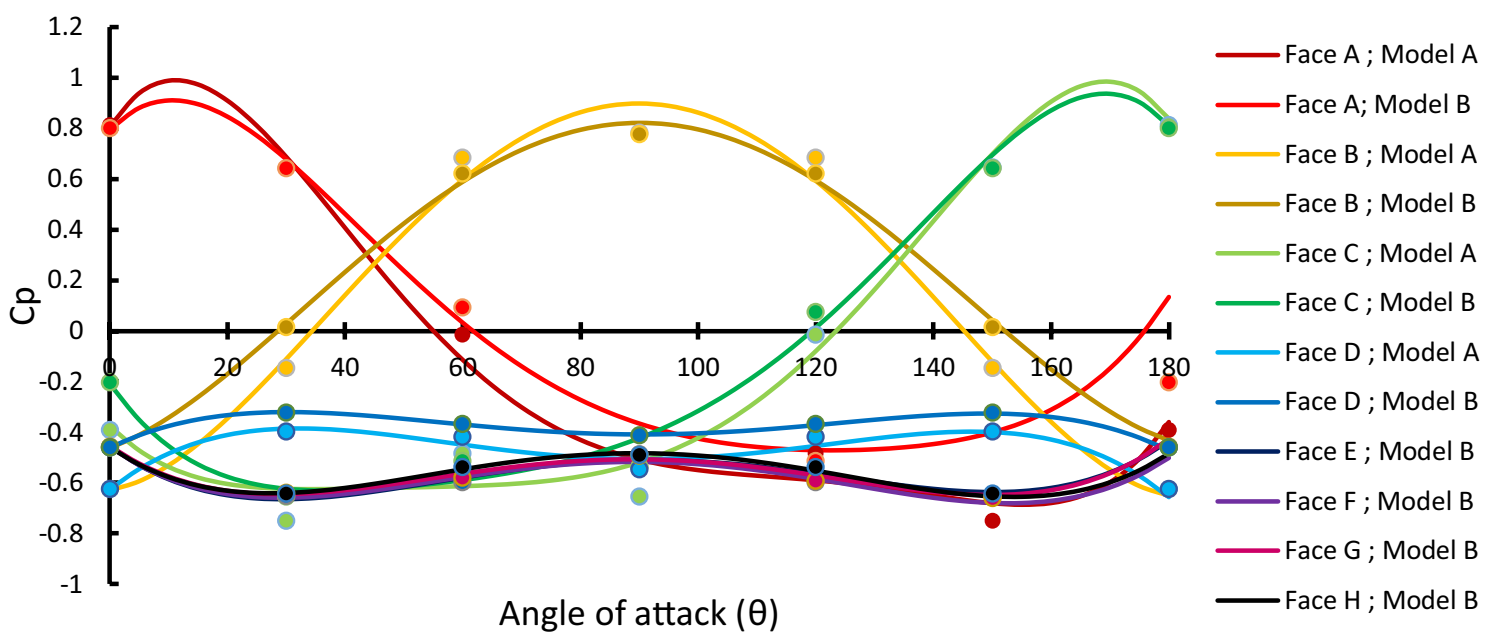

Fig. 13 Plot of numerical data points and derived equations of mean pressure coefficient for Models A and B

Table 2 Least-squares polynomials of pressure coefficient for each face of Models A and B

\begin{tabular}{|c|c|c|c|c|c|c|c|}
\hline Model & $\boldsymbol{\alpha}_{0}$ & $\alpha_{1}$ & $\alpha_{2}$ & $\alpha_{3}$ & $\alpha_{4}$ & $\alpha_{5}$ & $R^{2}$ \\
\hline \multicolumn{8}{|l|}{ Face A } \\
\hline Model A & 0.806389 & 0.035764 & -0.00203 & $2.81 \times 10^{-5}$ & $-1.60 \times 10^{-7}$ & $3.30 \times 10^{-10}$ & 0.9771 \\
\hline Model B & 0.79448 & $2.34 \times 10^{-2}$ & $-1.36 \times 10^{-3}$ & $1.77 \times 10^{-5}$ & $-9.61 \times 10^{-8}$ & $1.95 \times 10^{-10}$ & 0.9863 \\
\hline \multicolumn{8}{|l|}{ Face B } \\
\hline Model A & -0.62981 & $4.21 \times 10^{-3}$ & $6.38 \times 10^{-4}$ & $-7.35 \times 10^{-6}$ & $2.04 \times 10^{-8}$ & $-6.87 \times 10^{-22}$ & 0.9866 \\
\hline Model B & -0.46317 & $8.58 \times 10^{-3}$ & $3.95 \times 10^{-4}$ & $-4.92 \times 10^{-6}$ & $1.37 \times 10^{-8}$ & $-4.48 \times 10^{-22}$ & 0.9973 \\
\hline \multicolumn{8}{|l|}{ Face $\mathrm{C}$} \\
\hline Model A & -0.37595 & -0.02281 & 0.000787 & $-1.27 \times 10^{-5}$ & $9.47 \times 10^{-8}$ & $-2.41 \times 10^{-10}$ & 0.9747 \\
\hline Model B & -0.20919 & -0.03276 & 0.000946 & $-1.29 \times 10^{-5}$ & $8.74 \times 10^{-8}$ & $-2.13 \times 10^{-10}$ & 0.9879 \\
\hline \multicolumn{8}{|l|}{ Face D } \\
\hline Model A & -0.62601 & 0.018239 & -0.00045 & $3.84 \times 10^{-6}$ & $-1.07 \times 10^{-8}$ & $3.11 \times 10^{-22}$ & 0.9433 \\
\hline Model B & -0.46122 & 0.011159 & -0.00028 & $2.46 \times 10^{-6}$ & $-6.84 \times 10^{-9}$ & $2.00 \times 10^{-22}$ & 0.9979 \\
\hline \multicolumn{8}{|l|}{ Face E } \\
\hline Model B & -0.45512 & -0.01711 & 0.000445 & $-3.90 \times 10^{-6}$ & $1.12 \times 10^{-8}$ & $-1.71 \times 10^{-12}$ & 0.9834 \\
\hline \multicolumn{8}{|l|}{ Face $\mathrm{F}$} \\
\hline Model B & -0.45755 & -0.01651 & 0.00043 & $-3.76 \times 10^{-6}$ & $1.04 \times 10^{-8}$ & $-7.36 \times 10^{-23}$ & 0.9569 \\
\hline \multicolumn{8}{|l|}{ Face $\mathrm{G}$} \\
\hline Model B & -0.45512 & -0.01566 & 0.000411 & $-3.58 \times 10^{-6}$ & $9.62 \times 10^{-9}$ & $1.71 \times 10^{-12}$ & 0.9834 \\
\hline \multicolumn{8}{|l|}{ Face $\mathrm{H}$} \\
\hline Model B & -0.45952 & -0.01565 & 0.000424 & $-3.75 \times 10^{-6}$ & $1.04 \times 10^{-8}$ & $3.24 \times 10^{-23}$ & 0.9933 \\
\hline
\end{tabular}

second-order polynomial using least-squares regression method as discussed in Appendix.

The polynomials are in the form of $C_{p}=\alpha_{0}+\alpha_{1} \theta+\alpha_{2} x+\alpha_{11} \theta^{2}+\alpha_{22} x^{2}+\alpha_{12} x \theta$. Where $\theta$ is the angle of attack, which varies from $0^{\circ}$ to $180^{\circ}$ and $\mathrm{x}$ is the height of opening varies from 0 to $500 \mathrm{~mm}$. But for $x=0$, the building becomes Model B and so we can use the equations of Table 2. For $x>0$, i.e. when the inflow of wind through the opening is significant, we can use the equations of Table 3 .

The variation of wind effects for different heights of the frontal opening is low for higher wind incidence angles. So, for obtaining more accurate curve fitting polynomials, we have separated the range of wind incidence angle from $0^{\circ}$ to $60^{\circ}$ and from $60^{\circ}$ to $180^{\circ}$. The polynomial coefficients along with the regression coefficients $\left(R^{2}\right)$ for different faces are shown in Table 3 . It is found that most of the 
Table 3 Least-square polynomials of pressure coefficient for each face of Model C

\begin{tabular}{|c|c|c|c|c|c|c|c|c|}
\hline \multicolumn{9}{|c|}{$C_{p}=\alpha_{0}+\alpha_{1} \theta+\alpha_{2} x+\alpha_{11} \theta^{2}+\alpha_{22} x^{2}+\alpha_{12} x \theta$, where $0 \mathrm{~mm}<x \leq 500 \mathrm{~mm}$} \\
\hline Face & Angle of attack & $\boldsymbol{\alpha}_{0}$ & $\alpha_{1}$ & $\alpha_{2}$ & $\alpha_{11}$ & $\boldsymbol{\alpha}_{22}$ & $\alpha_{12}$ & $\boldsymbol{R}^{2}$ \\
\hline \multirow[t]{2}{*}{ Face A } & $0^{\circ} \leq \theta \leq 60^{\circ}$ & 0.59627 & -0.00231 & $9.24 \times 10^{-7}$ & -0.00019 & $3.65 \times 10^{-7}$ & $7.26 \times 10^{-7}$ & 0.9952 \\
\hline & $60^{\circ}<\theta \leq 180^{\circ}$ & 1.57160 & $-3.41 \times 10^{-2}$ & $-2.43 \times 10^{-4}$ & $1.33 \times 10^{-4}$ & $1.05 \times 10^{-6}$ & $-3.58 \times 10^{-6}$ & 0.9145 \\
\hline \multirow[t]{2}{*}{ Face B } & $0^{\circ} \leq \theta \leq 60^{\circ}$ & -0.61844 & 0.022658 & $6.97 \times 10^{-4}$ & $-8.56 \times 10^{-5}$ & $-1.53 \times 10^{-6}$ & $6.04 \times 10^{-6}$ & 0.9920 \\
\hline & $60^{\circ}<\theta \leq 180^{\circ}$ & -0.49380 & $2.84 \times 10^{-2}$ & $-1.92 \times 10^{-4}$ & $-1.59 \times 10^{-4}$ & $4.11 \times 10^{-7}$ & $-1.42 \times 10^{-6}$ & 0.9924 \\
\hline \multirow[t]{2}{*}{ Face C } & $0^{\circ} \leq \theta \leq 60^{\circ}$ & -0.30069 & $-5.60 \times 10^{-3}$ & $-5.27 \times 10^{-4}$ & $-2.28 \times 10^{-5}$ & $6.09 \times 10^{-7}$ & $6.89 \times 10^{-6}$ & 0.9042 \\
\hline & $60^{\circ}<\theta \leq 180^{\circ}$ & -1.662 & $1.66 \times 10^{-2}$ & $-3.44 \times 10^{-4}$ & $-1.38 \times 10^{-5}$ & $7.94 \times 10^{-7}$ & $-9.60 \times 10^{-7}$ & 0.9485 \\
\hline \multirow[t]{2}{*}{ Face D } & $0^{\circ} \leq \theta \leq 60^{\circ}$ & -0.33627 & 0.00158 & -0.00101 & $-5.35 \times 10^{-5}$ & $4.76 \times 10^{-7}$ & $1.42 \times 10^{-5}$ & 0.9430 \\
\hline & $60^{\circ}<\theta \leq 180^{\circ}$ & -0.67667 & $4.16 \times 10^{-3}$ & $3.91 \times 10^{-4}$ & $-1.67 \times 10^{-5}$ & $4.70 \times 10^{-7}$ & $-6.15 \times 10^{-6}$ & 0.9031 \\
\hline \multirow[t]{2}{*}{ Face E } & $0^{\circ} \leq \theta \leq 60^{\circ}$ & -0.42726 & 0.01359 & -0.00108 & -0.00028 & $2.66 \times 10^{-6}$ & $-2.97 \times 10^{-6}$ & 0.9014 \\
\hline & $60^{\circ}<\theta \leq 180^{\circ}$ & -0.76319 & $2.20 \times 10^{-3}$ & $-1.55 \times 10^{-3}$ & $-3.32 \times 10^{-6}$ & $3.70 \times 10^{-6}$ & $9.12 \times 10^{-7}$ & 0.9244 \\
\hline \multirow[t]{2}{*}{ Face F } & $0^{\circ} \leq \theta \leq 60^{\circ}$ & -0.61709 & $1.29 \times 10^{-2}$ & $3.48 \times 10^{-3}$ & $-2.48 \times 10^{-4}$ & $-2.38 \times 10^{-6}$ & $-1.57 \times 10^{-5}$ & 0.9263 \\
\hline & $60^{\circ}<\theta \leq 180^{\circ}$ & 0.02360 & -0.01074 & 0.000674 & $4.51 \times 10^{-5}$ & $4.50 \times 10^{-7}$ & $-4.61 \times 10^{-6}$ & 0.9235 \\
\hline \multirow[t]{2}{*}{ Face G } & $0^{\circ} \leq \theta \leq 60^{\circ}$ & -0.37080 & 0.01173 & 0.002781 & $-2.99 \times 10^{-4}$ & $-9.71 \times 10^{-7}$ & $-1.06 \times 10^{-5}$ & 0.9800 \\
\hline & $60^{\circ}<\theta \leq 180^{\circ}$ & 0.01673 & -0.01185 & 0.001048 & $5.25 \times 10^{-5}$ & $1.27 \times 10^{-6}$ & $-9.31 \times 10^{-6}$ & 0.9017 \\
\hline \multirow[t]{2}{*}{ Face $\mathrm{H}$} & $0^{\circ} \leq \theta \leq 60^{\circ}$ & -0.69793 & 0.020195 & 0.003624 & $-2.67 \times 10^{-4}$ & $-2.27 \times 10^{-6}$ & $-2.18 \times 10^{-5}$ & 0.9757 \\
\hline & $60^{\circ}<\theta \leq 180^{\circ}$ & 0.19899 & $-1.26 \times 10^{-2}$ & $1.49 \times 10^{-3}$ & $5.03 \times 10^{-5}$ & $-2.57 \times 10^{-7}$ & $-7.72 \times 10^{-6}$ & 0.9388 \\
\hline
\end{tabular}

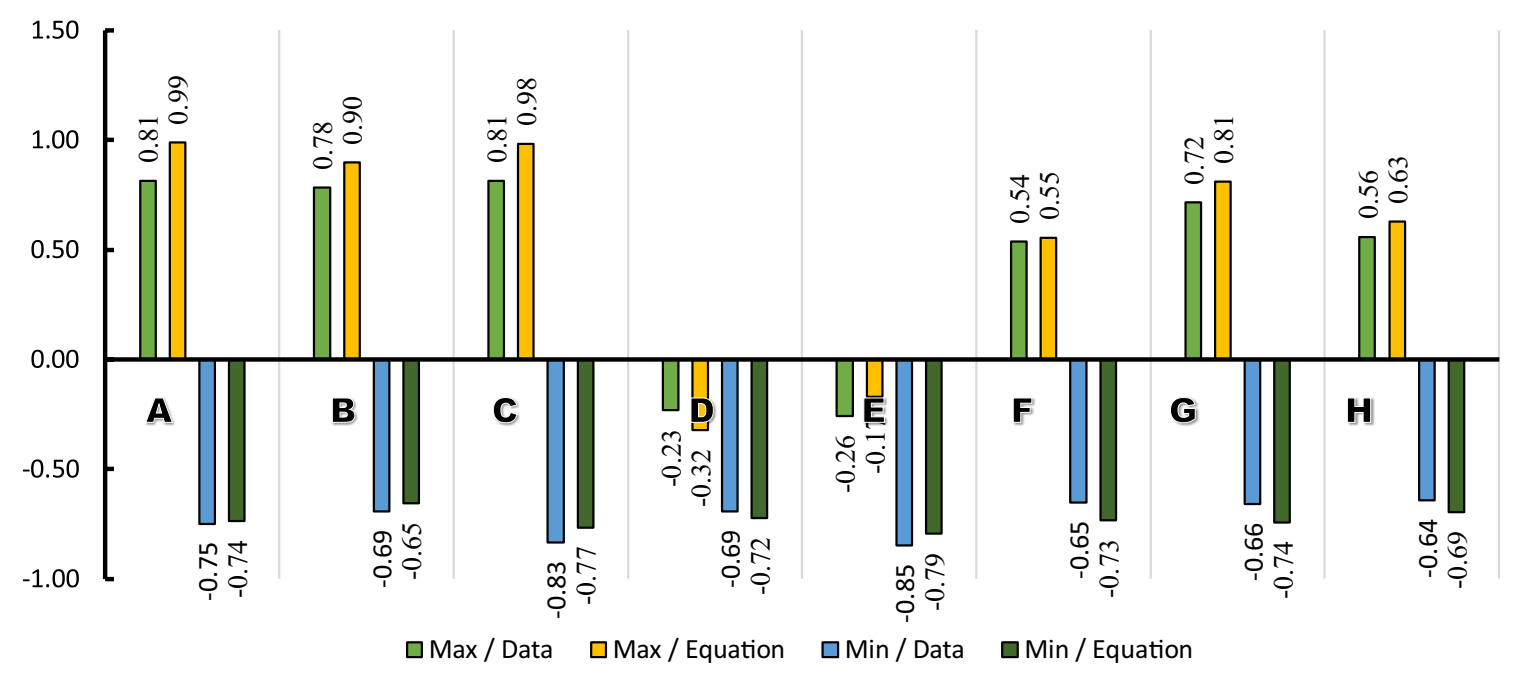

Fig. 14 Comparison of maximum and minimum mean pressure coefficients of different faces from numerical data and derived equations

polynomials are fitted well. Least accuracy in terms of $R^{2}$ value is found for Face $\mathrm{E}\left(0^{\circ} \leq \theta \leq 60^{\circ}\right)$ because of its varying surface area and separation of inflow wind inside the courtyard. However, all $R^{2}$ values are greater than 0.9 which is very much acceptable to construct a model with least-squares regression polynomial.

The comparison of the maximum and minimum values of mean pressure coefficients obtained from numerical data and derived equations is shown in Fig. 14, and has found that the deviation is within the allowable limit.

Force coefficient $\left(C_{\mathrm{f}}\right)$ is determined by the formula $C_{\mathrm{f}}=\frac{F}{P \times A}$, where ' $F$ ' is the value of total force exported from ANSYS CFX in the desired direction, ' $P$ ' is the wind pressure and ' $A$ ' is the projected surface area to the wind. $C_{\mathrm{f}}$ along two perpendicular directions $X$ (perpendicular to Face A) and $Y$ (parallel to Face A) are tabulated in Table 4.

The force coefficients along the $X$ and $Y$ directions are fitted as the second-order polynomial of form $C_{f}=\alpha_{0}+\alpha_{1} \theta+\alpha_{2} x+\alpha_{11} \theta^{2}+\alpha_{22} x^{2}+\alpha_{12} x \theta$. To obtain more accurate results, two different sets of equations are formed for $0^{\circ} \leq \theta \leq 60^{\circ}$ and $60^{\circ}<\theta \leq 180^{\circ}$ and shown in Table 5. The $R^{2}$ values are found to be greater than 0.9. So, 
Table 4 Force coefficients for each faces of different building models for various wind angles

\begin{tabular}{|c|c|c|c|c|c|c|c|c|c|}
\hline Model & $\theta$ & $C_{\mathrm{f}, \mathrm{x}}$ & $C_{\mathrm{f}, \mathrm{y}}$ & $\theta$ & $C_{\mathrm{f}, \mathrm{x}}$ & $C_{\mathrm{f}, \mathrm{y}}$ & $\theta$ & $C_{\mathrm{f}, \mathrm{x}}$ & $C_{\mathrm{f}, \mathrm{y}}$ \\
\hline Model A & $0^{\circ}$ & 1.195 & -0.023 & $30^{\circ}$ & 1.134 & 0.145 & $60^{\circ}$ & 0.425 & 0.841 \\
\hline Model B & & 0.975 & -0.005 & & 0.999 & 0.173 & & 0.516 & 0.860 \\
\hline Model C $(X=0.1 \mathrm{~m})$ & & 1.308 & -0.010 & & 1.117 & 0.203 & & 0.615 & 0.850 \\
\hline Model C $(X=0.2 \mathrm{~m})$ & & 1.537 & -0.007 & & 1.189 & 0.325 & & 0.717 & 0.898 \\
\hline Model C $(X=0.25 \mathrm{~m})$ & & 1.650 & -0.000 & & 1.131 & 0.469 & & 0.824 & 0.925 \\
\hline Model C $(X=0.3 \mathrm{~m})$ & & 1.720 & -0.010 & & 0.986 & 0.643 & & 0.866 & 0.952 \\
\hline Model C $(X=0.4 \mathrm{~m})$ & & 2.043 & -0.005 & & 1.073 & 0.711 & & 0.785 & 0.959 \\
\hline Model C $(X=0.5 \mathrm{~m})$ & & 2.266 & -0.017 & & 1.091 & 0.833 & & 0.942 & 0.977 \\
\hline Model A & $90^{\circ}$ & 0 & 1.188 & $120^{\circ}$ & -0.425 & 0.841 & $150^{\circ}$ & -1.134 & 0.145 \\
\hline Model B & & -0.006 & 0.974 & & -0.516 & 0.860 & & -0.999 & 0.213 \\
\hline Model C $(X=0.25 \mathrm{~m})$ & & 0.124 & 1.070 & & -0.640 & 0.754 & & -0.891 & 0.313 \\
\hline Model C $(X=0.5 \mathrm{~m})$ & & 0.109 & 0.999 & & -0.241 & 0.961 & & -1.003 & 0.345 \\
\hline Model A & $180^{\circ}$ & -1.195 & -0.023 & & & & & & \\
\hline Model B & & -0.975 & -0.015 & & & & & & \\
\hline Model C $(X=0.25 \mathrm{~m})$ & & -1.214 & -0.018 & & & & & & \\
\hline Model C $(X=0.5 \mathrm{~m})$ & & -1.071 & -0.004 & & & & & & \\
\hline
\end{tabular}

Table 5 Least-squares polynomials of force coefficients for Model C (and Model B: $X=0 \mathrm{~mm}$ )

\begin{tabular}{|c|c|c|c|c|c|c|c|}
\hline \multirow[t]{2}{*}{ Angle of attack } & \multicolumn{7}{|c|}{$C_{f}=\alpha_{0}+\alpha_{1} \theta+\alpha_{2} x+\alpha_{11} \theta^{2}+\alpha_{22} x^{2}+\alpha_{12} x \theta$, where $0 \mathrm{~mm} \leq x \leq 500 \mathrm{~mm}$} \\
\hline & $\boldsymbol{\alpha}_{0}$ & $\alpha_{1}$ & $\alpha_{2}$ & $\alpha_{11}$ & $\boldsymbol{\alpha}_{22}$ & $\alpha_{12}$ & $\boldsymbol{R}^{2}$ \\
\hline \multicolumn{8}{|l|}{$C_{\mathrm{f}, \mathrm{x}}$} \\
\hline $0^{\circ} \leq \theta \leq 60^{\circ}$ & 1.116248 & -0.01521 & 0.002388 & $1.26 \times 10^{-4}$ & $-8.05 \times 10^{-7}$ & $-2.88 \times 10^{-5}$ & 0.9134 \\
\hline $60^{\circ}<\theta \leq 180^{\circ}$ & 2.432911 & -0.03609 & 0.000938 & $9.27 \times 10^{-5}$ & $5.59 \times 10^{-7}$ & $-7.76 \times 10^{-6}$ & 0.9823 \\
\hline \multicolumn{8}{|l|}{$C_{\mathrm{f}, \mathrm{y}}$} \\
\hline $0^{\circ} \leq \theta \leq 60^{\circ}$ & -0.11434 & 0.015678 & 0.000412 & $-2.26 \times 10^{-5}$ & $1.46 \times 10^{-7}$ & $3.78 \times 10^{-6}$ & 0.9336 \\
\hline $60^{\circ}<\theta \leq 180^{\circ}$ & 0.286216 & 0.01674 & $-5.96 \times 10^{-5}$ & $-1.06 \times 10^{-4}$ & $-2.04 \times 10^{-7}$ & $1.97 \times 10^{-6}$ & 0.9299 \\
\hline
\end{tabular}

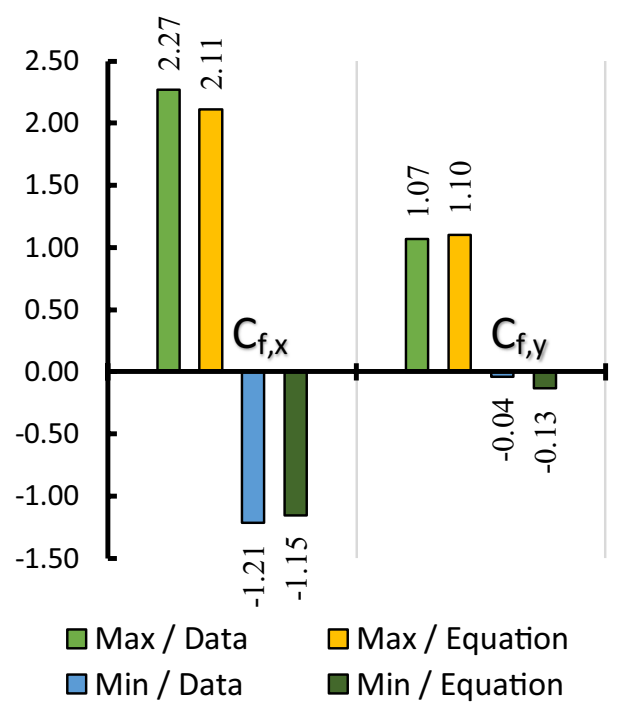

Fig. 15 Comparison of maximum and minimum force coefficients from numerical data and derived equations we can easily construct a model with least-squares regression polynomial.

The comparison of the maximum and minimum values of $C_{\mathrm{f}, \mathrm{x}}$ and $C_{\mathrm{f}, \mathrm{y}}$ obtained from numerical data and derived equations is shown in Fig. 15 and has found that the deviation is within the allowable limit.

Figure 16 illustrates the graphical output provided by postreg command of MATLAB. This output provides how the polynomials are fitted with the given data.

Here, due to scarcity of space only output vs target graphs for force coefficients is provided. The data points are plotted as some open circles. The best linear fit is indicated by a dashed line. The perfect fit (when output equal to targets) is indicated by the red solid line. From these four figures of output vs target graph, we have found that it is very difficult to distinguish the best linear fit line from the perfect fit line, because these fits are very good.

The combined graphs from these fitted polynomials along the $X$ and $Y$ directions are plotted in Fig. 17. $C_{\mathrm{f}, \mathrm{x}}$ decreases 


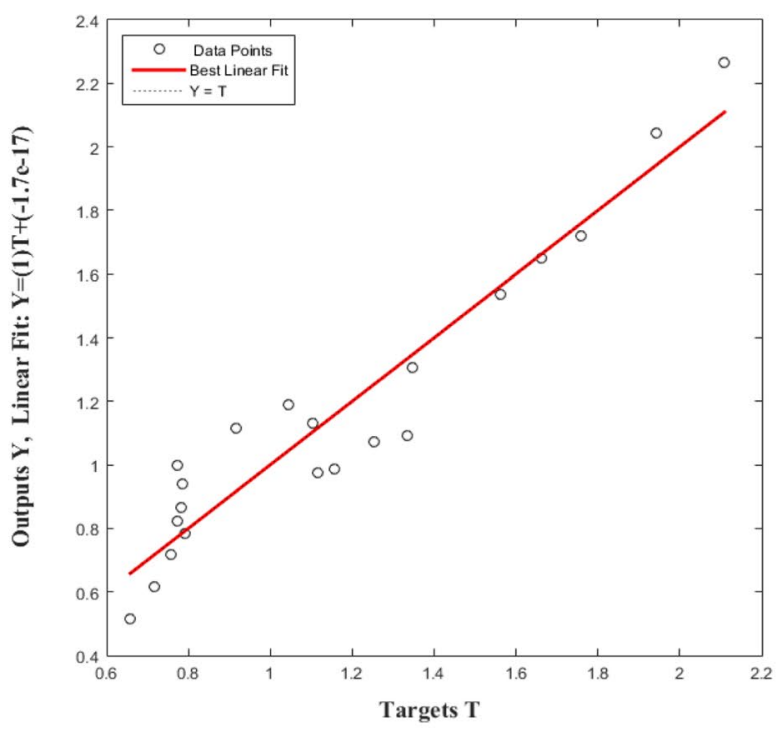

(a) $C_{f, x}\left(0^{\circ} \leq \theta \leq 60^{\circ}\right)$

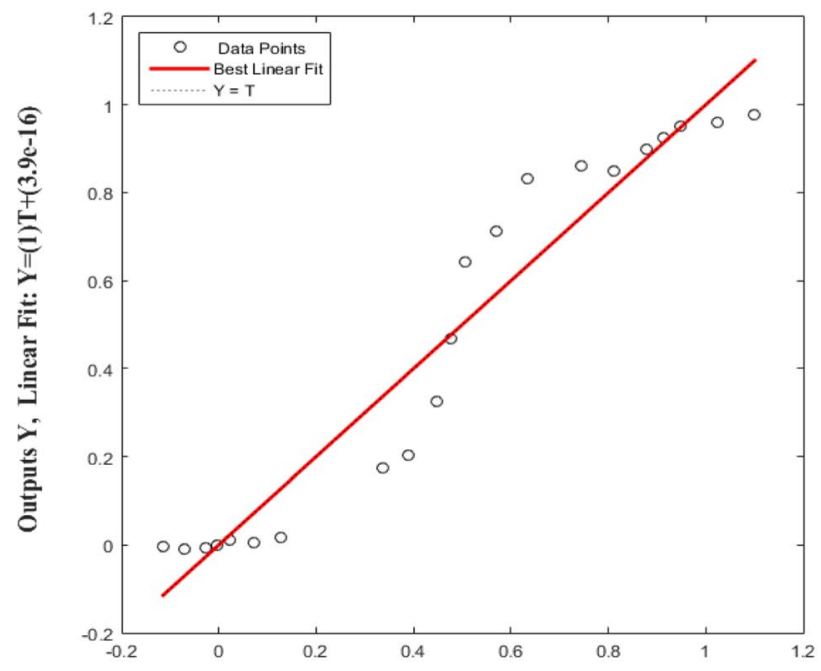

(c) $C_{f, y}\left(0^{\text {argets }} \stackrel{\text { T }}{\underline{1}} \leq 60^{\circ}\right)$

Fig. 16 Output vs target graph for force coefficients

with the increase in angle of attack. But for $0^{\circ}$ wind incidence angle, it increases with the increase in opening and obtains the maximum value of 2.27 at $X=0.5 \mathrm{~m}$. The value of $C_{\mathrm{f}, \mathrm{y}}$ is almost zero at $\theta=0^{\circ}$ wind incidence angle. Then it increases up to $\theta=90^{\circ}$ and decreases again and becomes almost 0 at $\theta=180^{\circ}$. From numerical data, it is found that force coefficient $\left(C_{\mathrm{f}}\right)$ along the $X$ direction has a maximum value of 2.267 for Model $C(x=0.5 \mathrm{~m})$ at $0^{\circ}$ wind angle and the same along the $Y$ direction is extreme for Model A at $90^{\circ}$ wind incidence angle with a value of 1.188 . But from fitted polynomials, it is found that $C_{\mathrm{f}}$ along the $X$ direction

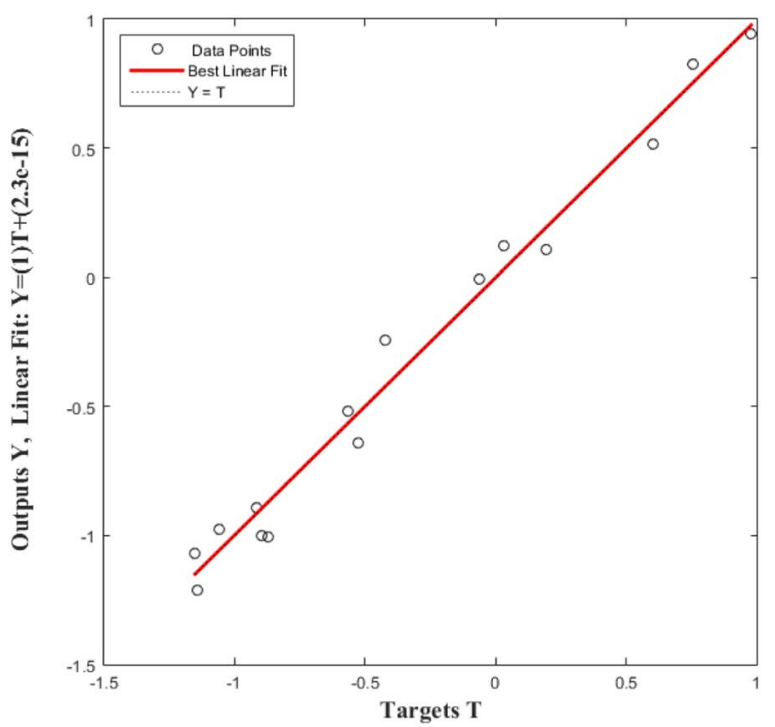

(b) $C_{f, x}\left(60^{\circ} \leq \theta \leq 180^{\circ}\right)$

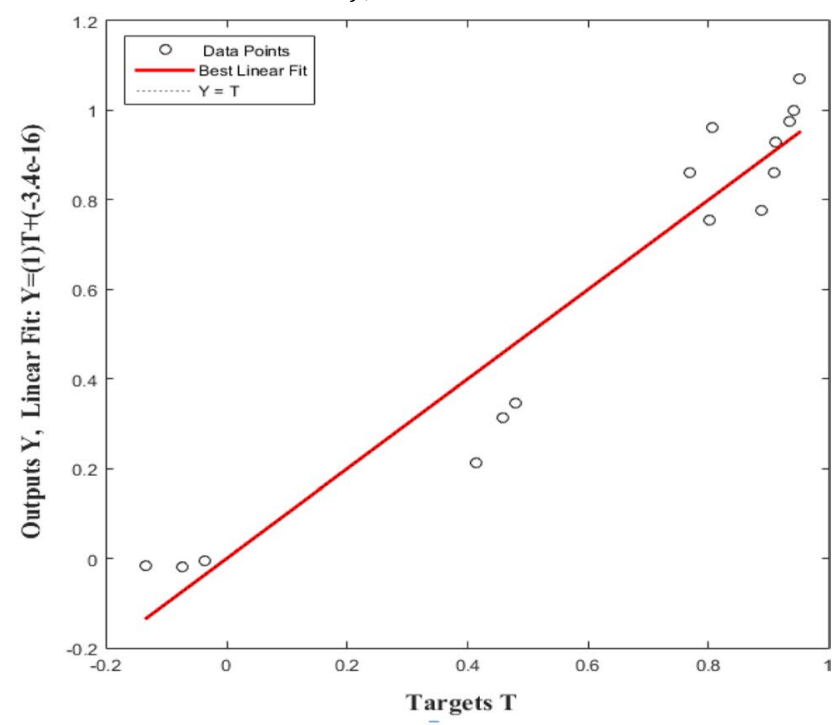

(d) $C_{f, y}\left(60^{\circ} \leq \theta \leq 180^{\circ}\right)$

has a maximum value of 2.11 for $\operatorname{Model} C(x=0.5 \mathrm{~m})$ at $0^{\circ}$ wind angle and the same along the $Y$ direction is extreme for Model $\mathrm{C}(x=0.5 \mathrm{~m})$ at $60^{\circ}$ wind incidence angle with a value of 1.1.

Graphical plots representing effect of change of wind incidence angle and area of opening on different faces of the rectangular plan shaped tall building are shown in Figs. 18 and 19. Pressure on each face has been compared along the vertical centreline for different cases. The comparison along the perimeter has also been carried out at $0.125,0.25$ and $0.375 \mathrm{~m}$ height from the base of the building model. Only 
Fig. 17 Variation of force coefficients with wind incidence angle and height of opening

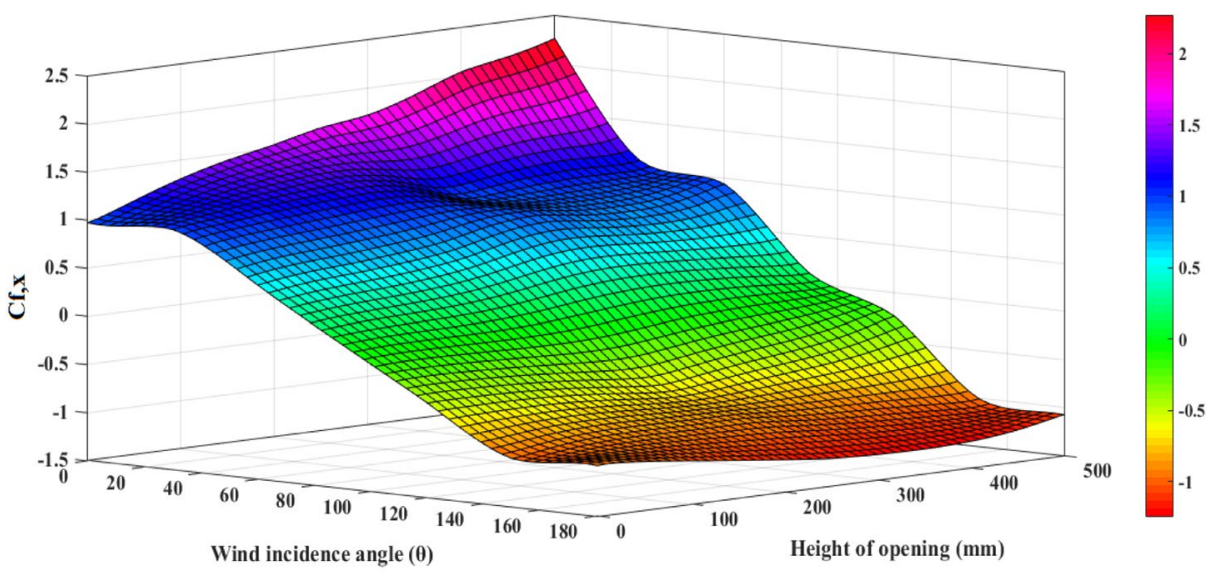

(a) Force coefficient along $\mathrm{x}$ direction $\left(\mathrm{C}_{\mathrm{f}, \mathrm{x}}\right)$

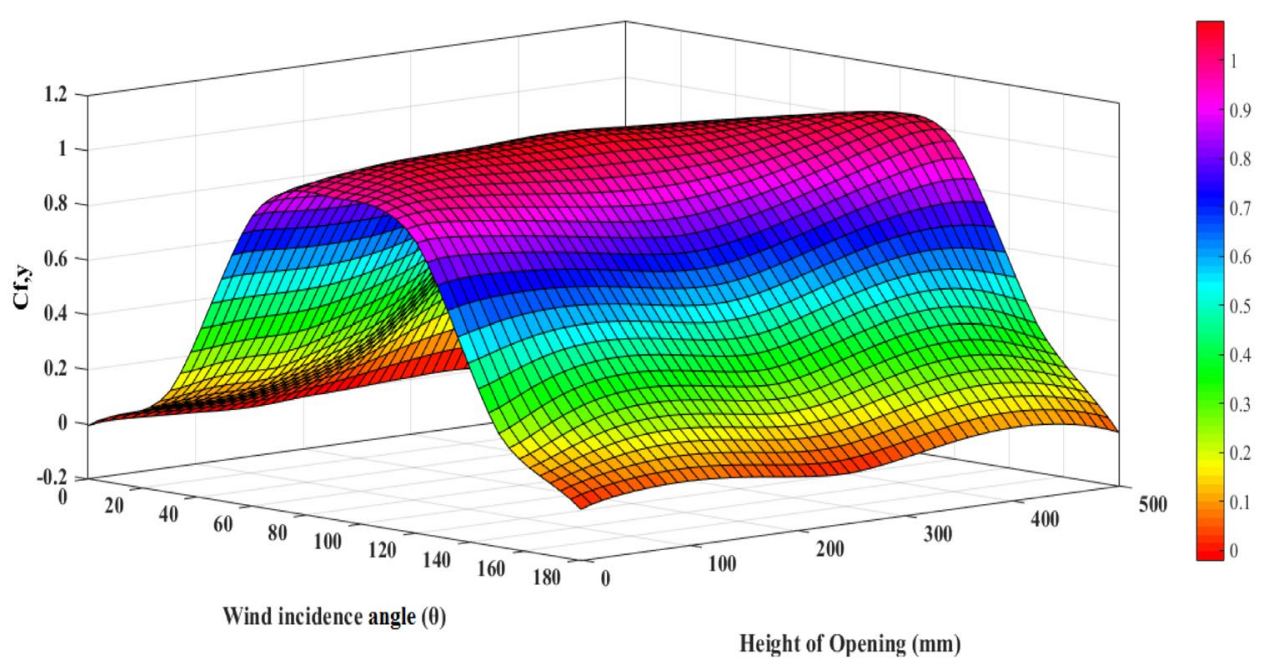

(b) Force coefficient along y direction $\left(\mathrm{C}_{\mathrm{f}, \mathrm{y}}\right)$

some cases of $0^{\circ}, 30^{\circ}$ and $60^{\circ}$ are used for the comparison as the effect of variation is low for higher wind angles.

With the change in angle of attack, different faces change their position and the variation of pressure coefficients along horizontal and vertical centrelines also changes accordingly. For the same wind incidence angle, the nature of pressure on Face A does not experience much variation for different models. For Faces B, C and D, the variation is also very low. Face $\mathrm{E}$ of Model $\mathrm{C}$ experiences more suction due to the separation of incoming flow and formation of vortices inside the courtyard. Faces F, G and H experience negative pressure for zero opening. But with the increase in opening, the pressure gradually increases on all these faces. From vertical and horizontal pressure lines, it is found that the pressure in different positions of Face $\mathrm{F}$ is highly irregular in nature and its unevenness is higher than other inner faces such as $G$ and $\mathrm{H}$. For some cases, the average $C_{\mathrm{p}}$ value of Faces F, G and $\mathrm{H}$ can be very small, but for design purposes these faces should be analysed thoroughly as the variation of pressure at different positions of these faces is very high. From comparison along horizontal lines, it is also found that pressure variation on the outside faces is similar; only magnitudes of pressure coefficient increase with the increase in height.

\section{Conclusion}

This paper described the pressure variation on all the surfaces of rectangular plan shaped tall building in the presence of courtyard and opening. CFD Simulation has been done by ANSYS CFX software. $k-\varepsilon$ and SST model have been used to validate the data with different international standards. As $k-\varepsilon$ model gives more accurate result, it is used for the further numerical simulations. The significant outcomes of the current study are: 


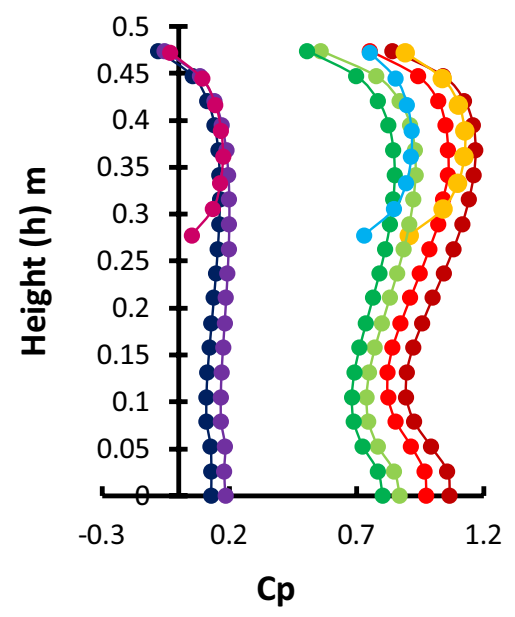

(a) Face $\mathrm{A}$

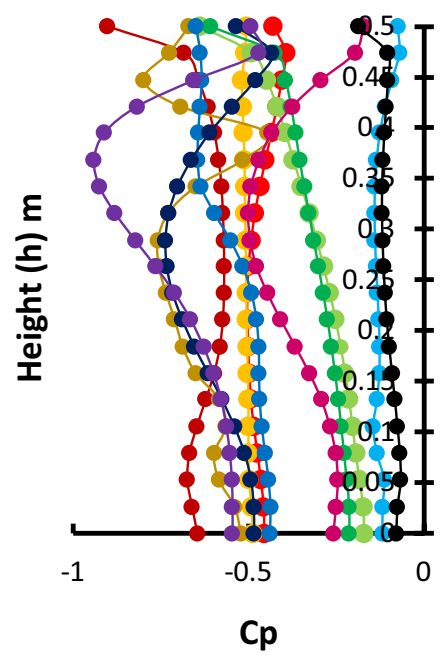

(d) Face D

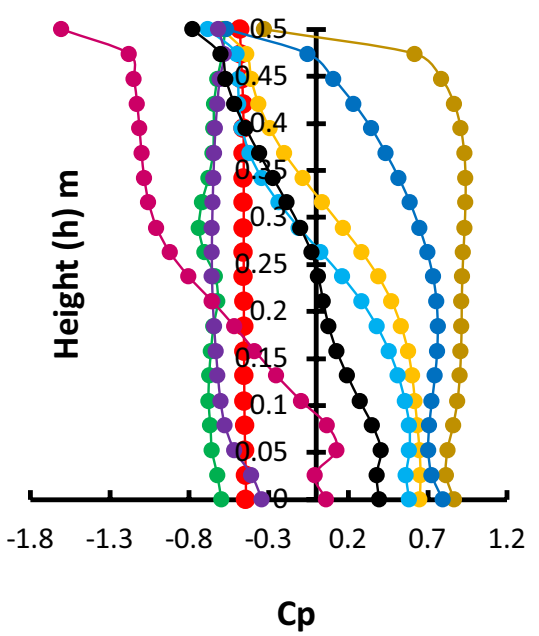

(g) Face G

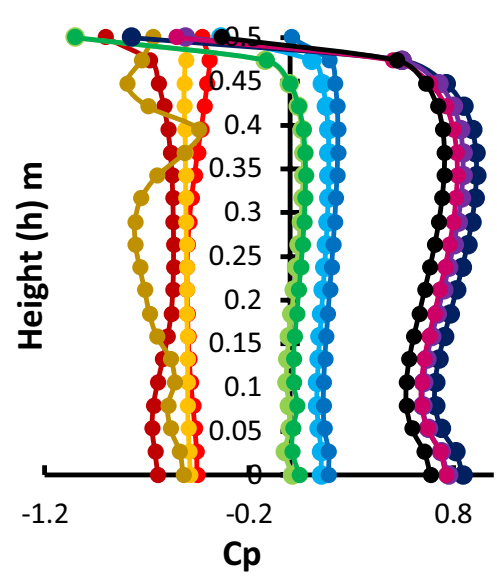

(b) Face B

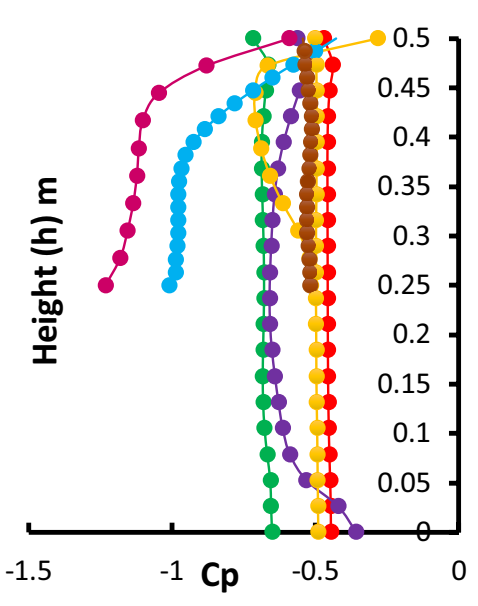

(e) Face E

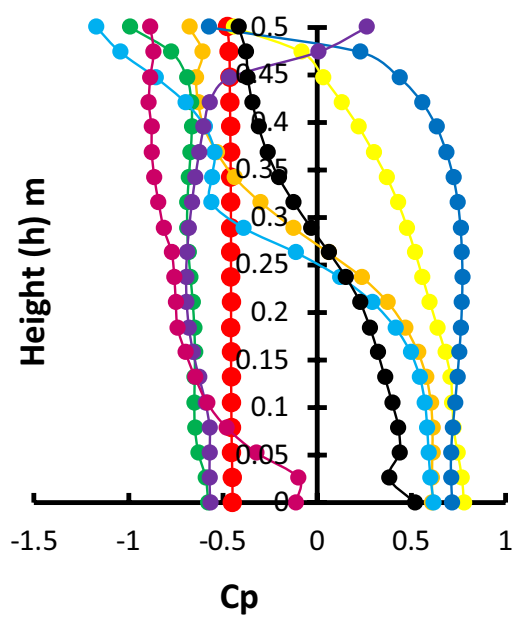

(h) Face $\mathrm{H}$

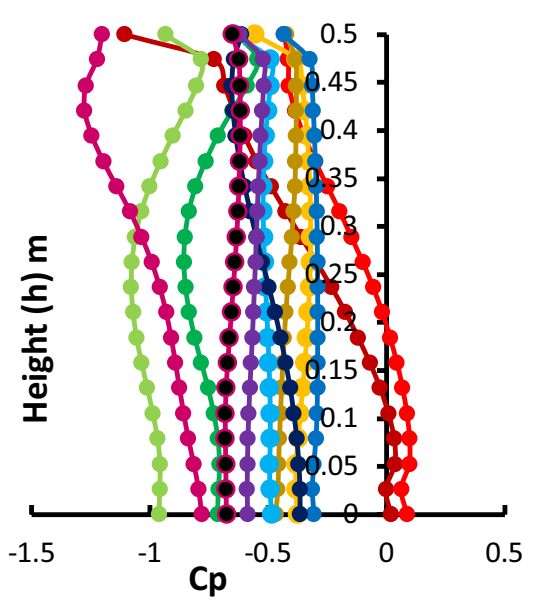

(c) Face $\mathrm{C}$

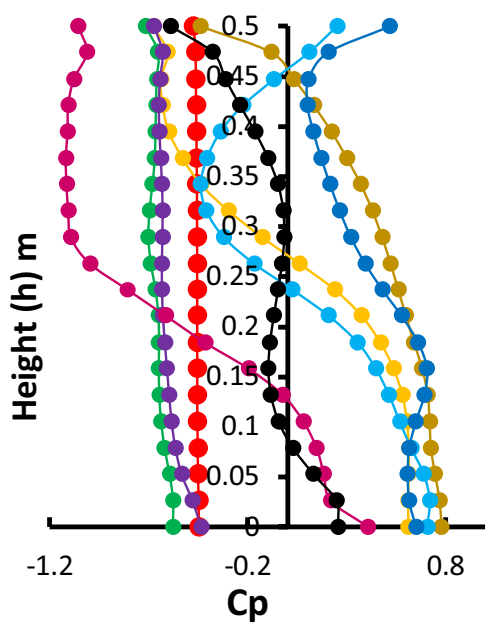

(f) Face F

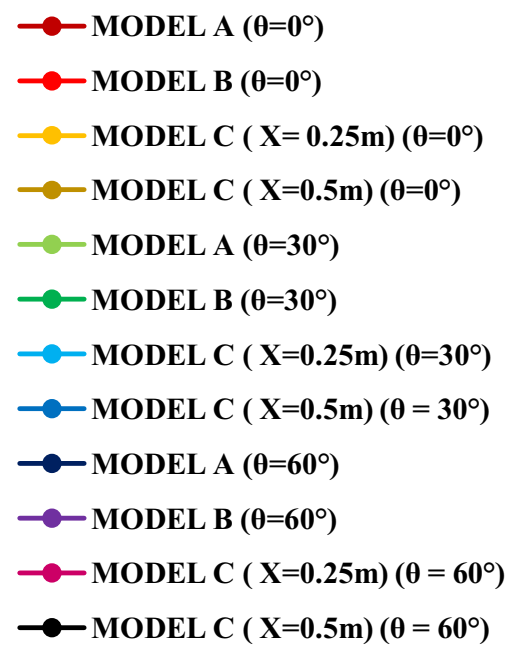

Fig. 18 Comparison of pressure coefficients along vertical centreline on different surfaces of various models for different angles of attack 


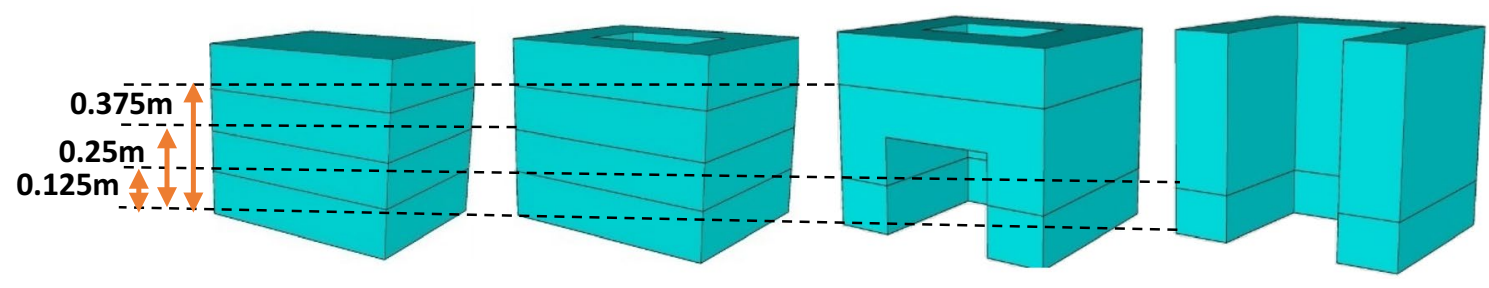

(a) Horizontal lines of different models along which pressure coefficients are compared

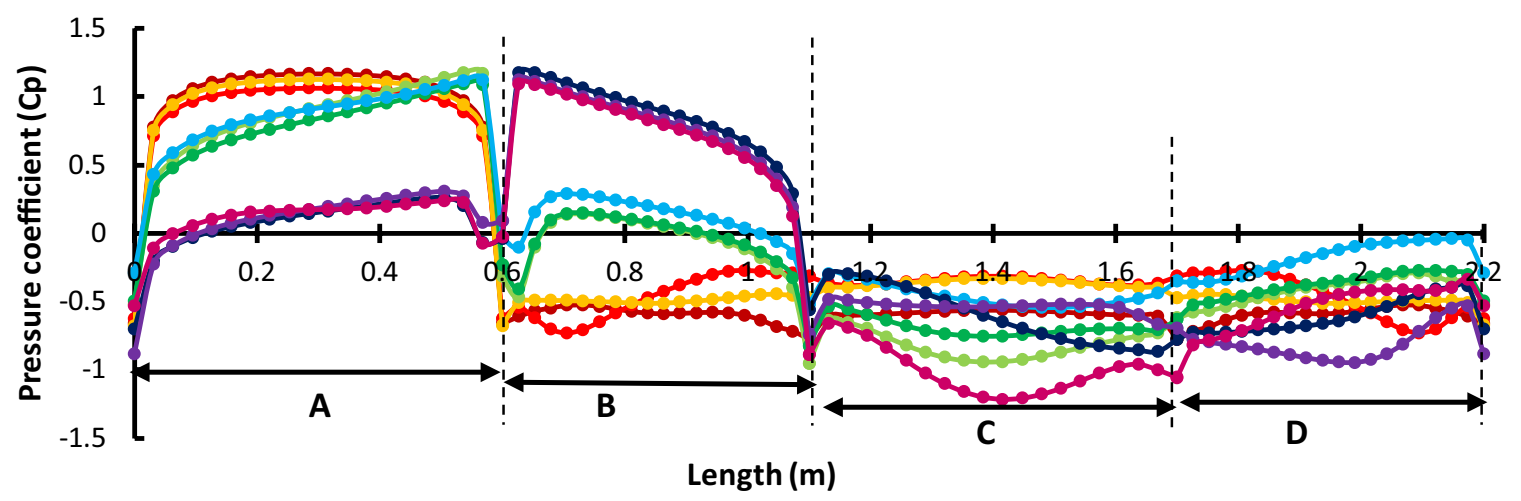

(b) Variation of pressure coefficients along perimeter at $0.375 \mathrm{~m}$ above base of MODEL A, MODEL B and MODEL C (X=0.25m)

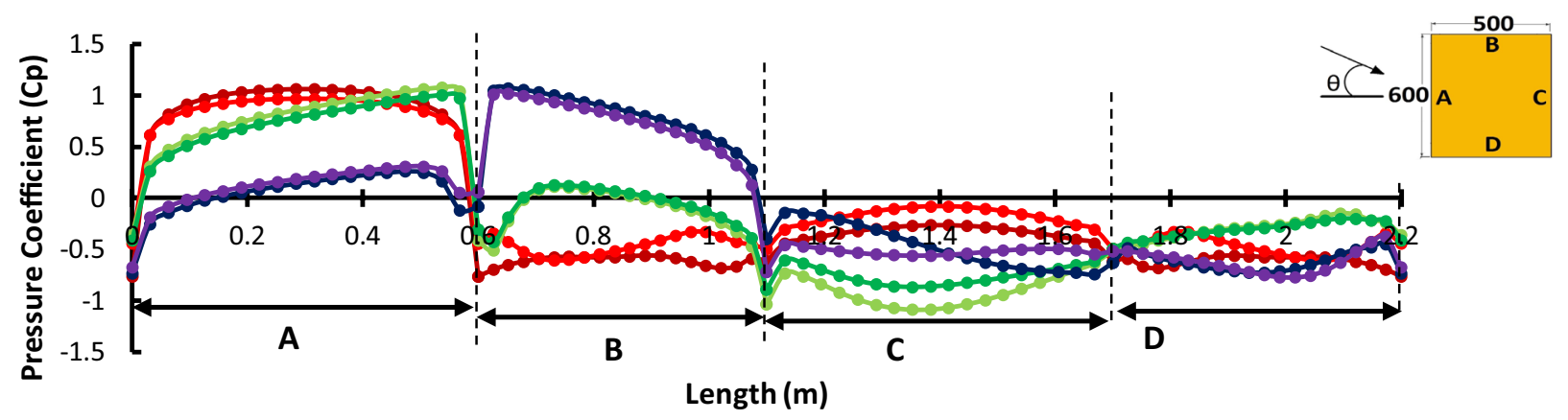

(c) Variation of pressure coefficients along perimeter at $0.250 \mathrm{~mm}$ above base of MODEL A and MODEL B

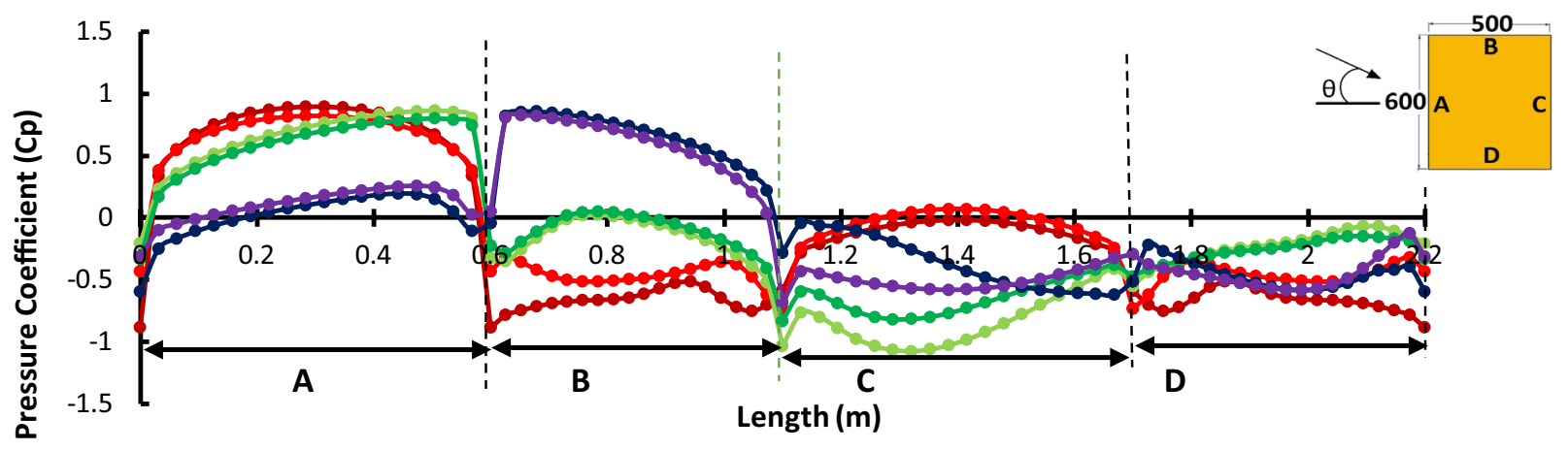

(d) Variation of pressure coefficients along perimeter at $0.125 \mathrm{~m}$ above base of MODEL A and MODEL B

Fig. 19 Variation of pressure coefficients along perimeter of different models 


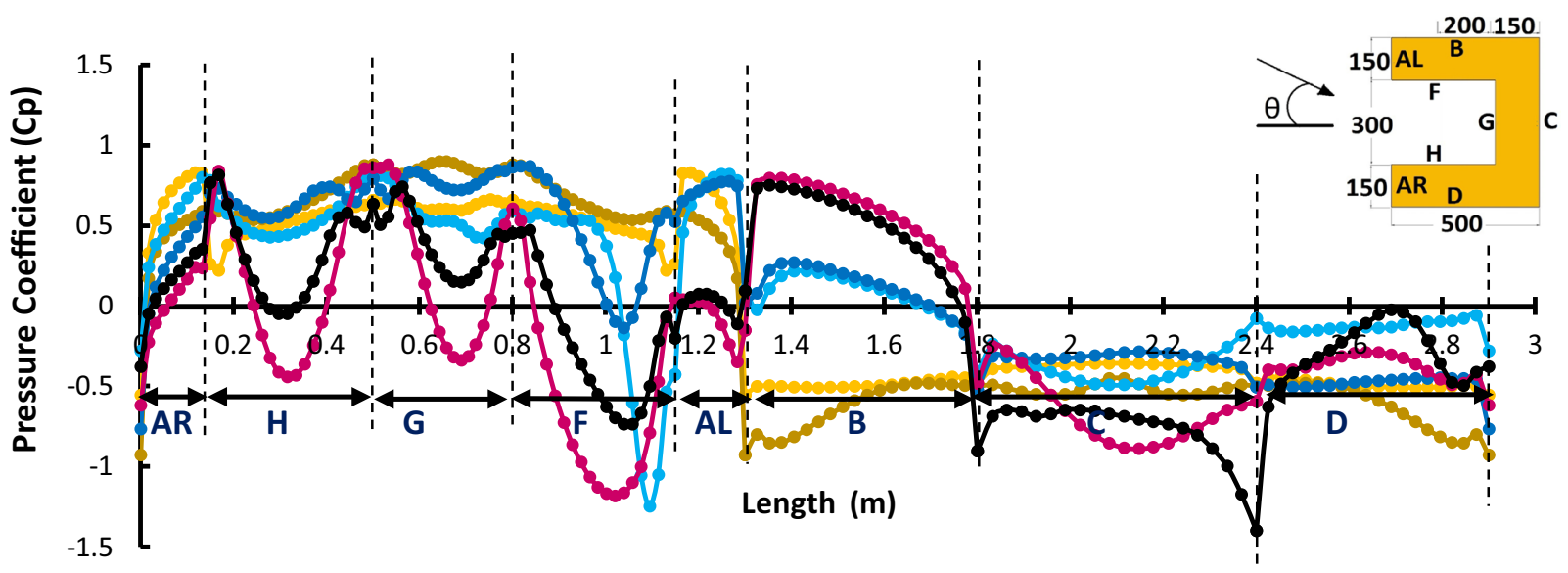

(e) Variation of pressure coefficients along perimeter at $0.125 \mathrm{~m}$ above base of MODEL C $(\mathrm{X}=0.25 \mathrm{~m})$ and MODEL C $(\mathrm{X}=0.5 \mathrm{~m})$

\begin{tabular}{|c|c|c|}
\hline$\rightarrow-M O D E L A\left(\theta=0^{\circ}\right)$ & $\rightarrow-M O D E L$ B $\left(\theta=0^{\circ}\right)$ & $\multimap$ MODEL C $(\mathrm{X}=0.25 \mathrm{~m})\left(\theta=0^{\circ}\right)$ \\
\hline$\multimap$ MODEL C $(\mathrm{X}=0.5 \mathrm{~m})\left(\theta=0^{\circ}\right)$ & $\multimap$ MODEL $A\left(\theta=30^{\circ}\right)$ & $\multimap$ MODEL B $\left(\theta=30^{\circ}\right)$ \\
\hline$\multimap$ MODEL C $(\mathrm{X}=0.25 \mathrm{~m})\left(\theta=30^{\circ}\right)$ & $\longrightarrow$ MODEL C $(\mathrm{X}=0.5 \mathrm{~m})\left(\theta=30^{\circ}\right)$ & $\multimap$ MODEL A $\left(\theta=60^{\circ}\right)$ \\
\hline$\multimap$ MODEL B $\left(\theta=60^{\circ}\right)$ & $\multimap$ MODEL C $(\mathrm{X}=0.25 \mathrm{~m})\left(\theta=60^{\circ}\right)$ & $\multimap$ MODEL C $(\mathrm{X}=0.5 \mathrm{~m})\left(\theta=60^{\circ}\right)$ \\
\hline
\end{tabular}

Fig. 19 (continued)

- From numerical data, it is found that maximum positive mean pressure coefficient of 0.81 occurs on Face A of Model A when the wind incidence angle is $0^{\circ}$, and maximum negative mean pressure coefficient of -0.85 occurs on Face $\mathrm{E}$ of Model C $(x=0.25 \mathrm{~m})$ at angle of attack $=60^{\circ}$.

- From numerical data, it is found that force coefficient $\left(C_{\mathrm{f}}\right)$ along the $X$ direction has a maximum value of 2.267 for Model $\mathrm{C}(x=0.5 \mathrm{~m})$ at $0^{\circ}$ wind angle and the same along the $Y$ direction is extreme for Model A at $90^{\circ}$ wind incidence angle with a value of 1.188.

- The windward faces experience positive pressure coefficients since undeviating wind force is coming there. Due of frictional flow separation and formation of vortices, the leeward and side faces are exposed to suction pressure.

- Formation of the vortices in the wake region happens in the presence of windward side pressure force and leeward side suction force. It causes the deflection of the body.

- Formation of vortices inside the inner courtyard also occurs due to the inward flow for $30^{\circ}$ and $60^{\circ}$ wind incidence angle.

- The maximum variation of pressure occurs on outside Faces A, B and C and inside Faces F, G and H.

- Not only the opening Face A, but also the other outer Faces B, C and D also change their $C_{\mathrm{p}}$ value due to the change in opening.

- Variations of pressure coefficient along horizontal and vertical centerline have also been studied. Different por- tions of Faces A, B, C and D do not experience a large variation of pressure for different areas of opening. But the lower portion of Faces F, G and H experience maximum increase in pressure with the increase in area of opening.

- Face E experiences more negative pressure in Model C due to flow separation and formation of vortex inside the courtyard.

- Furthermore, some analytical expression has been proposed for each of the face of different building models using least-squares regression polynomial. The force coefficients along the $X$ and $Y$ directions are also fitted as least-squares regression polynomial. Accuracy of the regression models is measured by $R^{2}$ value. These expressions are very suitable in predicting mean wind pressure coefficient, and force coefficient at any wind incidence angle varies between $0^{\circ}$ and $180^{\circ}$ for the building models.

- From curve fitting polynomials, it is found that maximum positive mean pressure coefficient of 0.99 occurs on Face A of Model A when the wind incidence angle is $11^{\circ}$ and maximum negative mean pressure coefficient of -0.79 occurs on Face $\mathrm{E}$ of Model C $(x=0.20 \mathrm{~m})$ at angle of attack $=60^{\circ}$. Force coefficient $\left(C_{\mathrm{f}}\right)$ along the $X$ direction has a maximum value of 2.11 for Model $\mathrm{C}(x=0.5 \mathrm{~m})$ at $0^{\circ}$ wind angle and the same along the $Y$ direction is extreme for Model C $(x=0.5 \mathrm{~m})$ at $60^{\circ}$ wind incidence angle with a value of 1.1 
Open Access This article is distributed under the terms of the Creative Commons Attribution 4.0 International License (http://creativeco mmons.org/licenses/by/4.0/), which permits unrestricted use, distribution, and reproduction in any medium, provided you give appropriate credit to the original author(s) and the source, provide a link to the Creative Commons license, and indicate if changes were made.

\section{Appendix}

The mean pressure coefficients for Models A and B vary with angle of attack only. So, we can form a single variable $k$ th degree polynomial, $y=\alpha_{0}+\alpha_{1}+\alpha_{2} x^{2}+\cdots+\alpha_{k} x^{k}$ for finding the values of $C_{\mathrm{p}}$ for different wind angles.

The variation of mean pressure coefficients and force coefficients for Model $\mathrm{C}$ is dependent on two variables, wind angle and height of opening. As there is an interaction between these two variables, so a second-order polynomial of form $y=\alpha_{0}+\sum_{j=1}^{k} \alpha_{j} x_{j}+\sum_{j=1}^{k} \alpha_{j j} x_{j}^{2}+\sum_{i<j} \sum_{j=2}^{k} \alpha_{i j} x_{i} x_{j}$ is required to predict the equations.

To evaluate the approximation functions, $\epsilon$ is incorporated to counter the approximation error.

So, by including $\epsilon$, both the equations can be expressed in a matrix form $\mathbf{y}=\mathbf{x} \boldsymbol{\alpha}+\epsilon$

Now, to find the coefficients of approximated equations, we have to use least-squares method.

By this approach, sum of the square of error of all simultaneous equation needs to be minimised.

We wish to find the vector of least-squares estimators, $S$, that minimises

$S=\sum_{i=1}^{n} \epsilon_{i}^{2}=\boldsymbol{\epsilon}^{T} \boldsymbol{\epsilon}=(\mathbf{y}-x \boldsymbol{\alpha})^{T}(\mathbf{y}-x \boldsymbol{\alpha})$.

For minimum error, partial differentiation of $S$ with respect to $\alpha$, must be zero.

After differentiation and simplification, the predicted least-squares estimator of $\boldsymbol{\alpha}$ is found as,

$\boldsymbol{\alpha}=\left(\mathbf{x}^{T} \mathbf{x}\right)^{-1} \mathbf{x}^{T} \mathbf{y}$.

And the predicted response values,

$\hat{\boldsymbol{y}}=x \boldsymbol{\alpha}$.

The accuracy of the fitted polynomial can be obtained from the $R^{2}$ value. It provides a measure of how well the observed outcomes are reflected by the model, based on the proportion of total variation of the outcomes.

If a dataset has $n$ values marked $y_{1} \ldots y_{n}$, each associated with a predicted (or modelled) value $\hat{y}_{1} \ldots \hat{y}_{n}$

Mean of observed data:

$\tilde{y}=\frac{1}{n} \sum_{i=1}^{n} y_{i}$
The sum of squares of residuals:

$\mathrm{SS}_{\mathrm{res}}=\sum_{i=1}^{n}\left(y_{i}-\hat{y}_{i}\right)^{2}$

The total sum of squares:

$\mathrm{SS}_{\mathrm{tot}}=\sum_{i=1}^{n}\left(y_{i}-\tilde{y}\right)^{2}$.

The most general definition of the coefficient of determination is,

$R^{2}=1-\frac{\mathrm{SS}_{\text {res }}}{\mathrm{SS}_{\text {tot }}}$

MATLAB software is used for all these curve fitting operations.

\section{References}

Amin JA, Ahuja AK (2011) Experimental study of wind-induced pressures on buildings of various geometries. Int J Eng Sci Technol 3(5):1-19

ANSYS, Inc. (2015) Tutorial for ANSYS CFX 16.0, 2015. http://www. ansys.com. Accessed 15 Apr 2017

AS, NZS: 1170.2 (2011) Structural design actions, part 2: wind actions. Standards Australia/Standards New Zealand, Sydney

ASCE: 7-16 (2016) Minimum design loads for buildings and other structures. Structural Engineering Institute of the American Society of Civil Engineering, Reston

Bhattacharyya B, Dalui SK, Ahuja AK (2014) Wind induced pressure on „E $E^{\text {ec }}$ plan shaped tall buildings. Jordon J Civil Eng $8(2): 120-134$

Chakraborty S, Dalui SK, Ahuja AK (2014) Wind load on irregular plan shaped tall building — a case study. Wind Struct Int J 19(1):59-73

Franke J, Hirsch C, Jensen A, Krus H, Schatzmann M, Westbury P, Miles S, Wisse J, Wright NG (2004) Recommendations on the use of CFD in wind engineering. In: COST action C14: impact of wind and storm on city life and built environment. von Karman Institute for Fluid Dynamics

Fu JY, Li QS, Wu JR, Xiao YQ, Song LL (2008) Journal of Wind Engineering field measurements of boundary layer wind characteristics and wind-induced responses of super-tall buildings. J Wind Eng Ind Aerodyn 96:1332-1358

Gomes Ã, Rodrigues AM, Mendes P (2005) Experimental and numerical study of wind pressures on irregular-plan shapes. J Wind Eng Ind Aerodyn 93:741-756

IS: 875 (2015) Indian standard code of practice for design loads (other than earthquake) for buildings and structures, part 3 (wind loads). Bureau of Indian Standards, New Delhi

Jones WP, Launder BE (1972) The prediction of laminarization with a two-equation model of turbulence. Int $\mathrm{J}$ Heat Mass Transf 15(1972):301-314

Kumar EK, Tamura Y, Yoshida A, Kim YC, Yang Q (2013) Journal of wind engineering experimental investigation on aerodynamic characteristics of various triangular-section high-rise buildings. J Wind Eng Ind Aerodyn 122:60-68

MATLAB 8.5, R (2015a). https://in.mathworks.com/

Montazeri H, Blocken B (2013) CFD simulation of wind-induced pressure coefficients on buildings with and without balconies: validation and sensitivity analysis. Build Environ 60:137-149 
Muehleisen RT, Patrizi S (2013) A new parametric equation for the wind pressure coefficient for low-rise buildings. Energy Build 57:245-249

Mukherjee S, Chakraborty S, Dalui SK, Ahuja AK (2014) Wind induced pressure on "Y" plan shape tall building. Wind Struct Int J 19(5):523-540

Paul R, Dalui SK (2016) Wind effects on "Z" plan-shaped tall building: a case study. Int J Adv Struct Eng. https://doi.org/10.1007/s4009 1-016-0134-9

Raj R, Ahuja AK (2013) Wind loads on cross shape tall buildings. J Acad Ind Res 2(2):111-113

Ramponi R, Blocken B (2012) CFD simulation of cross-ventilation for a generic isolated building: impact of computational parameters. Build Environ 53:34-48

Sarath KH, Selvi RS, Joseph AA, Ramesh BG, Srinivasa RN, Guru JJ (2015) Aerodynamic coefficients for a rectangular tall building under sub-urban terrain using wind tunnel. Asian J Civ Eng (BHRC) 17(3):325-333

Song J et al (2016) Aerodynamics of closely spaced buildings: with application to linked buildings. J Wind Eng Ind Aerodyn 149:1-16

Tominaga Y, Blocken B (2016) Wind tunnel analysis of flow and dispersion in cross-ventilated isolated buildings: impact of opening positions. J Wind Eng Ind Aerodyn 155:74-88

https://en.wikipedia.org/wiki/Coefficient_of_determination

Publisher's Note Springer Nature remains neutral with regard to jurisdictional claims in published maps and institutional affiliations. 